\title{
La licencia comercial para la instalación de los grandes establecimientos comerciales en Andalucía
}

\author{
María del Carmen Ortiz de Tena \\ Profesora Titular de Derecho Administrativo \\ Universidad de Sevilla
}

SUMARIO: 1.- LA LEY 6/2002, DE 16 DE DICIEMBRE, POR LA QUE SE MODIFICA LA LEY 1/1996, DEL COMERCIO INTERIOR DE ANDALUCÍA, Y SE CREA LA TASA POR TRAMITACIÓN DE LICENCIAS COMERCIALES. PRINCIPALES LÍNEAS DE LA REFORMA. 2.- EL NUEVO CONCEPTO LEGAL DE GRAN ESTABLECIMIENTO COMERCIAL. LOS ESTABLECIMIENTOS DE CARÁCTER COLECTIVO. LA ASIMILACIÓN DE LOS ESTABLECIMIENTOS DE DESCUENTO Y DE VENTA DE RESTOS DE FÁBRICA AL RÉGIMEN DE LOS GRANDES ESTABLECIMIENTOS. 2.1. Elementos definidores del "gran establecimiento": a) Superficie útil de exposición y venta al público. Problemas que plantea su cómputo. b) Población del municipio en el que el establecimiento se va a implantar. 2.2. Destino del establecimiento: ejercicio del comercio al por menor. 2.3. Supuestos excluidos. 2.4. Los establecimientos de carácter colectivo. 2.5. Regímenes específicos: los establecimientos de descuento o de venta de restos de fábrica. 3.- LA LICENCIA COMERCIAL ESPECÍFICA PARA LA INSTALACIÓN, APERTURA Y TRASLADO DE GRANDES ESTABLECIMIENTOS COMERCIALES. LA DENOMINADA SEGUNDA LICENCIA. 3.1. Las actividades sujetas a licencia comercial. 3.2. El traslado del procedimiento para el otorgamiento de la licencia comercial del ámbito municipal al autonómico. 3.3. La participación del Ayuntamiento en el procedimiento de otorgamiento de la licencia autonómica. 3.4. Comisión Asesora de Comercio Interior de Andalucía. 3.5. Examen de los criterios establecidos para la adjudicación: discrecionalidad y conceptos jurídicos indeterminados. Las medidas correctoras. 4.- LA PLANIFICACIÓN DEL COMERCIO INTERIOR: EL PLAN ANDALUZ DE ORIENTACIÓN COMERCIAL. 5.- LA DIRECTIVA EUROPEA SOBRE "SERVICIOS" Y SU INCIDENCIA EN LA REGULACIÓN DE LOS GRANDES ESTABLECIMIENTOS COMERCIALES. 6.- LAS GRANDES SUPERFICIES COMERCIALES Y EL DENOMINADO "URBANISMO COMERCIAL". 


\section{LA LEY 6/2002, DE 16 DE DICIEMBRE, POR LA QUE SE MODI- FICA LA LEY 1/1996, DEL COMERCIO INTERIOR DE ANDA- LUCÍA, Y SE CREA LA TASA POR TRAMITACIÓN DE LICEN- CIAS COMERCIALES. PRINCIPALES LÍNEAS DE LA REFORMA}

En diciembre del año 2001, la Comunidad Autónoma de Andalucía inició un proceso de reforma de su legislación en materia de comercio interior que culminó con la aprobación de la Ley 6/2002, de 16 de diciembre, por la que se modifica la Ley 1/1996, de 10 de enero, del Comercio Interior de Andalucía, y se crea la tasa por tramitación de licencias comerciales ${ }^{1}$. En esta línea de acción y con la finalidad de garantizar el éxito de la reforma pretendida, se aprobó una "moratoria" de un año para el otorgamiento de nuevas licencias de apertura de grandes establecimientos ${ }^{2}$.

La Ley del Comercio Interior de 1996 había abordado como tema central el de las grandes superficies comerciales, al que dedicaba su Título IV, posibi-

\footnotetext{
${ }^{1}$ Sobre las competencias de la Junta de Andalucía sobre Comercio interior vid. el trabajo de JIMÉNEZ BLANCO, A. sobre "Comercio", dentro del número extraordinario de la R.A.A.P. 2/2003, "Veinte años de vigencia del Estatuto de Autonomía de Andalucía. Desarrollo de las competencias autonómicas". Vol. I. Págs. 429 y ss. Con carácter general sobre el tema de las grandes superficies puede consultarse la obra colectiva dirigida por TORNOS MÁS, J. "Grandes establecimientos comerciales. Su ordenación e implantación”. Tecnos. Madrid, 2000. También CASES PALLARÉS, L. y PONS CÁNOVAS, F. "La implantación de grandes establecimientos comerciales". Marcial Pons. Madrid, 1998; MÍGUEZ MACHO, L. "La intervención administrativa en el comercio interior". IUSTEL. Madrid, 2005; OTONÍN BARRERA, F. "La ordenación de los establecimientos comerciales". La Ley. Madrid, 2005; y GINÉS VALERA ESCOBAR, "Articulación práctica en Andalucía de la previa licencia autonómica comercial en la tramitación de la licencia municipal de apertura”. IAAP. Sevilla, 2006.

${ }^{2}$ Tal decisión se insertó dentro de un paquete de medidas establecidas en la Ley de Acompañamiento de los Presupuestos Autonómicos para el año 2002 (Ley 15/2001, de 26 de diciembre, por la que se aprueban medidas fiscales, presupuestarias, de control y administrativas).

La aprobación de la moratoria aludida, que conllevaba la suspensión temporal de la libertad de comercio (en cuanto libertad de instalación, ampliación o traslado de las grandes superficies comerciales), se justificaba en la EM de la Ley de Acompañamiento, que señalaba: "Cualquier decisión tomada en base a los instrumentos normativos con los que actualmente se cuenta, fundamentalmente en lo que atañe al Título IV de la Ley antes referida, que regula las grandes superficies, vincularía el futuro desarrollo de la planificación comercial en Andalucía, lo que justifica, con el cumplimiento del principio de reserva de ley, el establecimiento de una moratoria...".

A pesar de ello, quizás debido a la incertidumbre que provocaba el anuncio del cambio legislativo, días antes de la entrada en vigor de la moratoria, se produjo una acumulación de nuevas solicitudes de licencias de apertura en la sede de los órganos autonómicos competentes.
} 
litándose el control de la Comunidad Autónoma de Andalucía sobre la instalación y apertura de tales establecimientos ${ }^{3}$. Con esta Ley, la Comunidad $\mathrm{Au}-$ tónoma de Andalucía seguía los pasos ya iniciados años antes por otras autonomías en orden a regular el fenómeno de los grandes establecimientos comerciales $^{4}$.

\footnotetext{
${ }^{3}$ Prácticamente en las mismas fechas en que se aprobaba la Ley del Comercio interior de Andalucía veía la luz la Ley estatal 7/1996 de Ordenación del Comercio Minorista. Entre los temas objeto de regulación de esta norma destaca el de la implantación de las grandes superficies comerciales, concretamente los Arts. 6 y 7, aplicables también a la Comunidad Autónoma de Andalucía en cuanto normas básicas. En realidad no todas las CCAA tenían atribuidas en un principio funciones legislativas sobre comercio interior, circunstancia que justificó la elaboración de una Ley estatal que posibilitara la intervención de tales CCAA en la instalación, apertura y traslado de los grandes establecimientos comerciales. El régimen establecido por la Ley 7/1996, en síntesis, es el siguiente: a) La Ley sujeta la apertura de "grandes establecimientos comerciales" a una licencia comercial específica cuyo otorgamiento corresponde a la Administración Autonómica (Art. 6.1); b) La Ley remite a las CCAA el establecimiento de los requisitos, en virtud de los cuales se otorgará la calificación de "gran establecimiento", pero establece en todo caso un concepto mínimo: los establecimientos comerciales sometidos a licencia serán aquellos que destinándose al comercio al por menor de cualquier clase de artículos, tengan una superficie útil para la exposición y venta al público superior a $2.500 \mathrm{~m} 2$ (Art. 2); c) La exigencia de esta licencia no es óbice para que las CCAA puedan someter a autorización administrativa otros supuestos relacionados con la actividad comercial (por ejemplo, para establecimientos más pequeños, o añadir controles adicionales); d) Los criterios fundamentales que deberán ponderarse por la autoridad autonómica para otorgar o denegar tal autorización son dos: existencia, o no, de un equipamiento comercial adecuado en la zona afectada por el nuevo emplazamiento y los efectos que éste pudiera ejercer sobre la estructura comercial de aquella; e) Además, la norma estatal somete en todo caso el otorgamiento de la mencionada licencia al Informe preceptivo del Tribunal de Defensa de la Competencia, que tendrá carácter no vinculante; f) Y finalmente, se señala que las Comunidades Autónomas con competencias en la materia podrán crear comisiones territoriales de equipamientos comerciales para informar sobre la instalación de grandes establecimientos. Esto último, con carácter potestativo.

En realidad, antes de la aprobación de la Ley 7/1996, diversas CCAA ya habían sometido la implantación de grandes superficies a controles específicos. Con la Ley estatal de Comercio Minorista se puede decir que la exigencia de licencia autonómica se extendió a todo el territorio nacional. En consecuencia, dado el carácter básico de la norma estatal, quedaría excluida la posibilidad de una desregulación total en la materia, renunciando a la intervención autorizatoria autonómica.
}

${ }^{4}$ Resultan muy interesantes las reflexiones que CASES PALLARÉS, L. y PONS CÁNOVAS, F. realizan en torno a estos establecimientos. Los citados autores observan una serie de tendencias en el control de la implantación de grandes establecimientos comerciales y que son las siguientes: el protagonismo creciente de la Administración autonómica en detrimento de la Administración local; el incremento de la intervención de la Administración Pública en el control del sector comercial en contraste con el proceso de liberalización económica que afecta a otros sectores; 
La intervención de la Comunidad Autónoma andaluza se instrumentaba mediante la exigencia de un informe previo y vinculante (en caso de ser desfavorable), emitido por la autoridad autonómica competente en materia de comercio, para la instalación, ampliación o traslado de una gran superficie comercial o centro comercial. Dicho informe se insertaba dentro del procedimiento de otorgamiento de la licencia municipal de apertura, regulado en los Arts. 22 a 25 de la L.R.B.R.L.

A medida que se fue aplicando la ley de comercio andaluza, fueron apareciendo problemas de diversa índole -como, por ejemplo, la interpretación del propio concepto de gran superficie comercial- que, junto con la rápida evolución de las formas de distribución comercial justificarían ${ }^{5}$ la reforma de aquella ${ }^{6}$.

la reducción de la superficie a partir de la que se considera al establecimiento comercial como una gran superficie. Esta reducción parece denotar que el problema del control de estos establecimientos no reside ya en una cuestión de superficie; la utilización de instrumentos de política territorial o de planificación para ejercer el control de las grandes superficies; la definición de los criterios a valorar para otorgar o denegar las autorizaciones en la LOCM estatal; la opción por el comercio intraurbano frente al periurbano; la generalización del control específico (licencia comercial) para toda forma de actividad comercial (Cfr. "La implantación de grandes establecimientos comerciales", Marcial Pons. Madrid, 1998, págs. 19 y ss.).

${ }^{5}$ Ciertamente, la necesidad de atraer la elección del consumidor y la búsqueda de una mejor posición competitiva en el mercado hacen del "comercio interior" un sector económico muy dinámico, susceptible de cambios rápidos, de renovación y adaptación a nuevas circunstancias, que deben ser objeto de regulación por el Ordenamiento Jurídico. Pero el desarrollo de las grandes superficies comerciales no ha sido el único cambio generado en este ámbito. Junto a él pueden citarse, sólo a modo de ejemplo, otros, como la constante aparición de nuevas modalidades de venta (a distancia, por teléfono, a través de ordenador, etc.); la decadencia y obsolescencia de los centros comerciales tradicionales; el crecimiento de la actividad comercial en las periferias urbanas en donde se concentra la población; la generalización de las formas comerciales de autoservicio; o el surgimiento de lo que se viene llamando "nuevas superficies comerciales" o centros comerciales de segunda generación, en los que la actividad comercial se hace progresivamente más compleja, en lo que a prestación de servicios se refiere, vinculándose con otros usos terciarios y de ocio.

${ }^{6}$ La Exposición de Motivos de la nueva Ley se refiere precisamente a estas razones, a saber: la experiencia adquirida en la aplicación de la anterior Ley y la rápida evolución de las formas de distribución comercial desde la aprobación de la misma.

Se trata de una reforma importante, aunque sólo afecta a determinados Títulos de Ley, sustancialmente el Título IV, sobre implantación de las grandes superficies comerciales y el Título VI regulador del régimen sancionador. Además, la nueva Ley establece una serie de modificaciones menores de carácter puntual referidas a la Inspección de comercio, al Registro de Comerciantes y Actividades Comerciales de Andalucía, y a las funciones de la Comisión Asesora de Comercio Interior de Andalucía. 
Las principales novedades que introduce la Ley 6/2002 en relación a las grandes superficies comerciales, que es el tema que ahora nos ocupa, son las siguientes:

- Se modifica el régimen administrativo de los grandes establecimientos mediante la sustitución del sistema vigente (único procedimiento referido a la licencia municipal de apertura, en el que se incardina el preceptivo Informe comercial de la Consejería competente en materia de comercio interior) por una nueva licencia comercial específica de la Administración Autonómica que deberá otorgarse antes de la solicitud de las correspondientes licencias municipales (todo ello en línea con la legislación establecida al respecto por otras Comunidades Autónomas).

- Se introduce un nuevo concepto de gran establecimiento comercial y se asimilan al régimen de los grandes establecimientos los establecimientos comerciales de descuento y de venta de restos de fábrica con superficie superior a $400 \mathrm{~m}^{2}$ (eso sí, sometidos a un procedimiento específico).

- Se añaden nuevos criterios de valoración para el otorgamiento de las licencias comerciales, entre los que destaca (como novedad también respecto a otras Comunidades Autónomas) el de "la integración del establecimiento en la estructura comercial existente mediante la valoración de las medidas correctoras que el promotor adopte frente al impacto que la instalación pudiera ocasionar al comercio previamente establecido en la zona de influencia”.

- En cuanto al procedimiento, destaca la participación de las Organizaciones más representativas del sector y la configuración de un Informe, preceptivo y vinculante, que debe emitir el Ayuntamiento en cuyo término se proyecte la actuación (el citado Informe se inserta ahora dentro del procedimiento tramitado por la Comunidad Autónoma).

- Se introduce una tasa autonómica que grava la tramitación de estas nuevas licencias.

- La Ley regula el Plan Andaluz de Orientación Comercial como instrumento clave para orientar la dotación de los grandes establecimientos sometidos a previa licencia comercial. 
- La nueva Ley ofrece una ordenación mucho más completa y detallada que la contenida en la versión de 1996.

Como puede observarse, las modificaciones son más profundas de lo que en un principio pudiera parecer. En realidad, la nueva Ley mantiene la filosofía de la intervención y control administrativo sobre la implantación de este tipo de establecimientos, sin duda con el ánimo de frenar o paliar al menos sus posibles efectos negativos; sin embargo, tal finalidad teleológica o si se prefiere tales funciones arbitrales, se pretenden alcanzar mediante la figura de los Planes de Orientación Comercial, que se presentan como el gran instrumento de racionalización de la actividad administrativa, capaz de reducir la discrecionalidad en la concesión de las licencias y en consecuencia incrementar la seguridad jurídica para los empresarios promotores de este tipo de establecimientos. Asimismo, el modo de la intervención, desde el punto de vista formal, también cambia, al trasladarse el procedimiento del ámbito municipal a la sede autonómica.

Hay que señalar, por otra parte, que la Comunidad Autónoma de Andalucía, con esta nueva ordenación que introduce, se aproxima a la trayectoria ya recorrida por la mayoría de las Comunidades Autónomas en lo que a regulación de grandes superficies se refiere. En este sentido, las modificaciones que acoge la Ley 6/2002, como ahora veremos, tienen claros precedentes en diversas leyes autonómicas reguladoras del comercio interior.

\section{EL NUEVO CONCEPTO DE GRAN ESTABLECIMIENTO CO- MERCIAL. LOS ESTABLECIMIENTOS DE CARÁCTER COLEC- TIVO. LA ASIMILACIÓN DE LOS ESTABLECIMIENTOS DE DESCUENTO Y DE VENTA DE RESTOS DE FÁBRICA AL RÉGI- MEN DE LOS GRANDES ESTABLECIMIENTOS}

Lo primero que interesa destacar es la trascendencia que tiene la fijación del concepto de "gran establecimiento comercial". No se trata de una cuestión baladí, sino todo lo contrario. Recordemos que la intervención autonómica (mediante la exigencia de la autorización comercial específica) se va a producir precisamente sobre los establecimientos que tienen tal carácter y no respecto a otros ${ }^{7}$,

\footnotetext{
${ }^{7}$ Los establecimientos comerciales pueden clasificarse según diversos criterios (carácter individual o colectivo, tipo de actividad comercial que se ejerza en ellos, tener o no acceso directo a la calle, etc.). Sin duda, la distinción más relevante, desde el punto de vista jurídico, es la que separa los "grandes establecimientos comerciales" del resto de establecimientos (ya sean medianos o pequeños). Esta diferenciación de establecimientos aparece plenamente recogida en el derecho positivo autonómico y en la Ley estatal del Comercio Minorista de 1996.
} 
por lo que los efectos jurídicos que se derivan de la calificación del establecimiento son notables ${ }^{8}$.

Partiendo de esta premisa, veamos cuál es la regulación autonómica. La nueva Ley introduce, en primer lugar, un cambio de denominación o de terminología. Antes hablaba de "grandes superficies comerciales", y ahora en cambio utiliza la expresión de "grandes establecimientos comerciales"10. La sustitución del término "superficies" por el de "establecimientos" tiene su explicación en la ampliación de los supuestos sometidos a licencia ${ }^{11}$; sin embargo, como ahora veremos, la "superficie" seguirá teniendo un valor atractivo y definidor del establecimiento objeto de intervención.

\subsection{Elementos definidores del "gran establecimiento"}

El concepto de "gran establecimiento comercial" se establece en el Art. 23, precepto que se redacta en unos términos mucho más precisos y detalla-

\footnotetext{
${ }^{8}$ Además del efecto citado, algunas normas autonómicas establecen otras singularidades en el régimen jurídico de los grandes establecimientos. Por ejemplo, en relación al régimen de fijación de los horarios comerciales (Cfr. MONTOYA MARTÍN, E, "Los horarios comerciales. La incertidumbre de su liberalización en el 2001". R.A.A.P. no 37). Para la citada autora esta diferenciación de régimen jurídico, en cuanto a la libertad de fijación de horarios se refiere, resulta discriminatoria.

${ }^{9}$ La denominación común "gran superficie comercial" es un concepto utilizado frecuentemente en diversos ámbitos y que ha servido para identificar una nueva generación de comercios de grandes dimensiones. En algunos casos, tal denominación se ha recogido expresamente en las leyes autonómicas de comercio; y en otros, el legislador prefiere emplear simplemente el término de "gran establecimiento comercial". No obstante, sigue siendo una expresión común, arraigada y válida, como definidora de un tipo de establecimiento comercial, objeto de mira y de preocupación por parte del legislador, del político y de la Administración.

${ }^{10}$ La misma rúbrica del Título IV ha variado. En la redacción originaria de la Ley 1/1996, se decía: "Grandes superficies comerciales", y ahora en cambio reza: "Establecimientos comerciales". Cierto es que el objeto de regulación, como ahora veremos, se amplía también a otro tipo de establecimientos.

Con una finalidad más sistemática y clarificadora el nuevo Título IV introducido por la Ley 6/2002, se inicia con un Capítulo I dedicado a fijar una serie de "Conceptos y categorías". Concretamente: Establecimientos comerciales (Art. 21); Superficie útil para la exposición y venta al público (Art. 22); Gran establecimiento comercial (Art. 23); Establecimiento de descuento (Art. 24).

${ }^{11}$ En la nueva Ley el régimen de sometimiento a licencia comercial específica no se ciñe sólo a las denominadas grandes superficies (aunque antes también se asimilaban los centros comerciales), sino que se extiende a otro tipo de establecimientos.
} 
dos que los empleados en $1996^{12}$. La regulación se ofrece más perfilada o reglamentista, en comparación a la de la norma antecesora. Dice así:

"1. A los efectos de esta Ley, tendrá la consideración de gran establecimiento comercial, con independencia de su denominación, todo establecimiento de carácter individual o colectivo en el que se ejerza la actividad comercial minorista que tenga una superficie útil para la exposición y venta al público superior a: a) 2.500 metros cuadrados, en municipio de más de 25.000 habitantes; b) 1.300 metros cuadrados, en municipios con una población de entre 10.000 y 25.000 habitantes; c) 1.000 metros cuadrados, en municipios de menos de 10.000 habitantes...”.

Conviene puntualizar, en primer lugar, que para el legislador tanto el nombre o denominación que se dé al establecimiento como el carácter individual o colectivo que tenga resultan cuestiones indiferentes a la hora de calificar un establecimiento comercial como "gran establecimiento". Lo verdaderamente definitivo no es eso.

Como puede observarse, el concepto que recoge la Ley se apoya sobre dos elementos: uno, su dimensión espacial, o más concretamente la superficie del establecimiento destinada al ejercicio de la actividad comercial minorista; $y$, dos, la población del municipio donde se pretende instalar el nuevo establecimiento. En la ley anterior, el concepto únicamente se definía por la referencia a la superficie de venta, sin aludir para nada al número de habitantes del municipio donde se fuera a ubicar ${ }^{13}$. Con esta modificación, la ley andaluza ha seguido el precedente marcado en este punto por otras legislaciones autonómicas.

Como es sabido no existe en nuestro país una noción homogénea de lo que sean grandes superficies o establecimientos comerciales. El concepto puede variar de una Comunidad Autónoma a otra y también respecto del que es-

\footnotetext{
${ }^{12}$ El concepto legal de los grandes establecimientos, de formulación aparentemente sencilla, al aplicarse en la práctica provocó numerosos problemas interpretativos y de otra índole, que tuvieron que ir sorteando las Comunidades Autónomas al otorgar o denegar las licencias de apertura y que en algunos casos motivaron las oportunas reformas normativas.

${ }^{13}$ Igual criterio sigue la vigente Ley 1/2002 del Comercio de Cantabria, que tampoco alude al elemento población y define los "grandes establecimientos comerciales" en base a su superficie de exposición y venta al publico, en este caso superior a $2500 \mathrm{~m}^{2}$ (Art. 6).
} 
tablece la ley estatal ${ }^{14}$. Hay, pues, una variedad terminológica y conceptual en las diferentes normas autonómicas y estatales que regulan el tema.

Las normas autonómicas sobre comercio interior ofrecen un concepto descriptivo y cuantitativo, más que sustantivo, de lo que se consideran "grandes superficies o establecimientos comerciales”. Estos establecimientos se caracterizan precisamente por la extensión en metros cuadrados de su superficie de venta al público en relación al número de habitantes del municipio en que se vayan a ubicar ${ }^{15}$.

El concepto legal de "gran superficie" viene expresado, por tanto, por la ecuación: superficie de venta y número de habitantes. El valor que la ley asig-

\footnotetext{
${ }^{14}$ La Ley estatal del Comercio minorista remite la fijación de los requisitos para la calificación de los grandes establecimientos a la legislación autonómica; sin embargo, establece un contenido mínimo obligatorio en todo caso. Contenido que tiene carácter de norma básica. Así reza el Art. 2.3 de la citada Ley: "Las Comunidades Autónomas establecerán los requisitos, en virtud de los cuales se otorgará la calificación de gran establecimiento. En todo caso tendrán esta consideración, a efectos de las autorizaciones y de lo establecido en la normativa mercantil, los establecimientos comerciales, que destinándose al comercio al por menor de cualquier clase de artículos, tengan una superficie útil para la exposición y venta al público superior a los 2.500 metros cuadrados". Es decir, el legislador autonómico con competencias para ello, podría en hipótesis añadir nuevos requisitos para la calificación de grandes establecimientos a efectos de autorizaciones, pero respetando siempre ese mínimo común establecido en la norma básica estatal. Parece ser que lo que ha pretendido el legislador estatal es asegurar que fueran grandes establecimientos en todo caso los de más de $2.500 \mathrm{~m}^{2}$, remitiendo lo relativo a extensiones menores a la decisión del legislador autonómico. En Andalucía, el concepto originario de gran superficie era muy similar al de la Ley estatal.
}

La Sentencia del Tribunal Superior de Justicia del País Vasco núm. 681/2002, de 1 de julio, advierte que la Ley estatal de Ordenación del Comercio Minorista “... no sienta con carácter básico e indisponible para las Comunidades Autónomas un único concepto de gran establecimiento comercial...", “... señala como mínimo común denominador normativo para todo el territorio nacional, que tendrán la consideración de gran establecimiento comercial los de superficie superior a 2.500 metros cuadrados. A partir de ahí, deja expresamente a criterio del legislador territorial la completa definición del concepto, sin llegar a imponer criterios delimitadores, y concretamente sin limitar dicha potestad de configuración normativa reduciéndola al único criterio de la superficie...”.

${ }^{15}$ BERENGUER FUSTER, L. critica estas referencias a los municipios de mayor o menor población, ya que con ello parece interpretarse que el gran establecimiento afecta exclusivamente al comercio del municipio en el que se encuentra enclavado, cuando la realidad es otra. Precisamente porque los efectos de las grandes superficies se considera que son supralocales, comarcales, es por lo que se justifica la intervención de la Administración autonómica en el otorgamiento de licencias (Cfr. "El régimen de los grandes establecimientos en la Ley de Ordenación del Comercio Minorista" en el Vol. Col. "Libre competencia y Ley de Ordenación del Comercio Minorista en España”. Madrid 1977. Pág. 110). 


\title{
na a cada una de estas dos variables, y la relación resultante, será diversa según la Comunidad Autónoma de que se trate ${ }^{16}$.
}

\section{Aunque aparentemente el criterio definidor del gran establecimiento es puramente cuantitativo (o espacial si se prefiere) ${ }^{17}$, no se trata sólo de la di-}

\begin{abstract}
${ }^{16}$ Por poner algunos ejemplos, la Ley 9/1989, de 5 de octubre, de Ordenación de la Actividad Comercial en Aragón considera "grandes superficies: a) En las poblaciones con menos de veinte mil habitantes, aquellos establecimientos que, en su implantación o como consecuencia de ampliaciones posteriores, tengan una superficie de venta al público superior a los seiscientos metros cuadrados; b) En las poblaciones con más de veinte mil y menos de quinientos mil habitantes, aquellos establecimientos que, en su implantación o como consecuencia de ampliaciones posteriores, tengan una superficie de venta al público superior a los mil metros cuadrados; c) En las poblaciones con más de quinientos mil habitantes, aquellos establecimientos que, en su implantación o como consecuencia de ampliaciones posteriores, tengan una superficie de venta al público superior a los dos mil metros cuadrados" (Art. 14.1).

La Ley 10/2003, de Canarias, reguladora de la Licencia Comercial Específica, define a los "Grandes establecimientos" en su Art. 3, como aquellos cuya superficie útil de venta al público supere las siguientes dimensiones: A) En las islas de Gran Canaria y Tenerife: a) En los municipios con una población de hecho inferior a 20.000 habitantes, $750 \mathrm{~m}^{2}$. b) En los municipios con una población de hecho igual o superior a 20.000 habitantes e inferior a 200.000, $1.500 \mathrm{~m}^{2}$. c) En los municipios con una población de hecho igual o superior a 200.000 habitantes, $2.000 \mathrm{~m}^{2}$. B) En las islas de El Hierro y La Gomera: $500 \mathrm{~m}^{2}$. C) En las islas de Fuerteventura, Lanzarote y La Palma: a) En los municipios con una población de hecho inferior a 20.000 habitantes, $750 \mathrm{~m}^{2}$. b) En los municipios con una población de hecho igual o superior a 20.000 habitantes, $1.000 \mathrm{~m}^{2}$.

La Ley 7/1998, de 15 de octubre, de Comercio Minorista de Castilla-La Mancha en su Art. 3.1 (redacción dada por la Ley 1/2004, de 1 de abril) establece: «1. Tendrán la consideración de gran establecimiento comercial los establecimientos individuales dedicados al comercio minorista, polivalente o especializado, estén o no integrados en un establecimiento de carácter colectivo, que tengan una superficie útil para la venta y exposición de productos igual o superior a: -Los 2.000 $\mathrm{m}^{2}$ en los municipios con población igual o superior a los 25.001 habitantes. - Los $1.000 \mathrm{~m}^{2}$ en los municipios con población comprendida entre los 10.001 y 25.000 habitantes. - Los $750 \mathrm{~m}^{2}$ en los municipios que tengan una población igual o inferior a los 10.000 habitantes».

La Ley 16/2002, de 19 de diciembre, de Comercio de Castilla y León, define el concepto de gran establecimiento comercial en su Art. 17.1, estableciendo que tienen tal carácter: "a) Los establecimientos comerciales individuales o colectivos con una superficie de venta al público superior a 2.000 metros cuadrados en municipios de más de 50.000 habitantes. b) Los establecimientos comerciales individuales o colectivos con una superficie de venta al público igual o superior a 1.500 metros cuadrados en municipios con más de 10.000 y menos de 50.000 habitantes. c) Los establecimientos comerciales individuales o colectivos con una superficie de venta al público igual o superior a 1.000 metros cuadrados en municipios con menos de 10.000 habitantes".
\end{abstract}

${ }^{17}$ En opinión de RODRÍGUEZ VELARDE, B. circunscribirse al único referente de la dimensión no deja de ser un incorrecto e inconveniente reduccionismo. Existen otras características que también pueden tener importancia a efectos de racionalizar la distribución de equipamientos comerciales como, por ejemplo, ser especializado o polivalente, dedicarse al sector de la alimentación o al del bricolage... (Cfr. "Urbanismo comercial”. Jaén, 2002. Pág. 68). 
mensión o el tamaño del establecimiento. El gran establecimiento se somete a intervención precisamente porque se presupone que su implantación hipotéticamente puede producir también un "gran" impacto económico, social, territorial... cosa que en principio no debe ocurrir con el establecimiento pequeño o mediano. El legislador no define dicho impacto, simplemente señala un número de metros cuadrados, pero esa cantidad es expresiva de algo más. Por otra parte, la determinación de un número concreto de metros cuadrados, arriba o abajo, resulta una cuestión puramente convencional, que, en última instancia, responde a criterios de política comercial y que como hemos visto varía según la Comunidad Autónoma en que nos encontremos.

Ciertamente el tamaño del establecimiento comercial es relevante a la hora de valorar los efectos del nuevo comercio sobre el tejido comercial de la zona. Sin embargo, si lo que se pretende con la intervención administrativa es paliar posibles efectos negativos, no debe valorarse exclusivamente la superficie del establecimiento, ya que puede darse el caso por ejemplo, de que establecimientos pequeños pertenecientes a los mismos grupos empresariales, produzcan un efecto nocivo sobre el pequeño o mediano comercio local (pensemos en cadenas de establecimientos de pequeñas o medianas dimensiones que con el mismo o distinto nombre pertenecen a grupos empresariales que poseen un alto porcentaje en la cuota de mercado y que de hecho alteran notablemente la libre competencia). Este peligro parece que pretende evitarse en la Ley 10/2003 de Canarias que regula la Licencia Comercial Específica. Esta norma no sólo somete a licencia comercial a las grandes superficies, sino también a otro tipo de establecimientos, como son los "Establecimientos comerciales titularidad de empresas o grupos de empresas con una gran implantación comercial"18. En el caso de Andalucía estos supuestos no quedan sometidos expresamente a la licencia comercial autonómica.

a) Superficie útil para la exposición y venta al público. Problemas que plantea su cómputo.

El Art. 23 de la Ley andaluza considera gran establecimiento aquel cuya "superficie útil para la exposición y venta al público" supere un determinado

\footnotetext{
${ }^{18}$ Estos establecimientos se definen (Art. 5), como "aquellos establecimientos comerciales que no reuniendo los requisitos establecidos para la sujeción a las licencias en los supuestos contemplados en las letras a) y c) del apartado 1 del artículo 1 , sean explotados por personas físicas o jurídicas que ejerzan actividades comerciales dentro de la Comunidad Autónoma canaria en establecimientos que, en su conjunto, superen un total de $25.000 \mathrm{~m}^{2}$ de superficie de venta".
} 
número de metros cuadrados. La redacción originaria de la Ley de Comercio Interior de Andalucía (Art. 21.1) hablaba simplemente de "superficie de venta" que definía en su aptdo. 2 como "aquella en la que se almacenen artículos para su venta directa, esté cubierta o no, y sea utilizable efectivamente por el consumidor, exceptuando los aparcamientos". En la nueva versión dada a este precepto en el año 2002, el legislador andaluz optó por añadir a la expresión "superficie" el calificativo de "útil" 19 , y ofrecer una definición más detallada y minuciosa del concepto. La Ley sigue en este punto la línea de una ordenación reglamentista.

El cómputo de la superficie del establecimiento resulta determinante para calibrar ante qué tipo de establecimiento comercial estamos ("gran establecimiento" o simplemente establecimiento a secas) y en definitiva cuál es el régimen jurídico del mismo ${ }^{20}$. No es de extrañar por tanto que, desde la aprobación y entrada en vigor de las leyes de comercio interior (tanto la estatal como las autonómicas), esta cuestión haya planteado numerosos problemas interpretativos y suscitado controversias a la hora de su aplicación práctica. La picaresca ha tratado de eludir la exigencia de la autorización autonómica reduciendo incluso algunos metros cuadrados de superficie del establecimiento que se pretendía implantar (por ejemplo, construir superficies que no alcanzan los $2.500 \mathrm{~m}^{2}$, es decir de $\left.2.495 \mathrm{~m}^{2}\right)$.

Se ha discutido si dentro de la superficie computable habría que incluir o no los espacios destinados a accesos, escaparates o aparcamientos ${ }^{21}$. También se ha puesto en duda si habría que contar o dejar fuera los espacios destinados a la prestación de servicios.

\footnotetext{
${ }^{19}$ Expresión recogida por la Ley estatal de Ordenación del Comercio Minorista (LOCM) (Art. 2.3).

${ }^{20} \mathrm{El}$ número de metros cuadrados es lo que va a determinar si un establecimiento se somete o no a un régimen de programación y de autorización específico. Como ya hemos señalado no se trata de una cuestión menor, dados los efectos jurídicos que produce.

${ }^{21}$ BERENGUER FUSTER, L. (ob. cit. Pág. 107) considera que "deben computarse todas las superficies que sean necesarias para el gran establecimiento, ya que el legislador únicamente ha querido excluir del cómputo la superficie de los almacenes, los aparcamientos y las oficinas. La restante superficie debe computarse aun cuando desde la mera interpretación literal no esté estrictamente destinada a la exposición y venta de los artículos en venta. Parece que la superficie computable debe ser, pues, toda aquella que puede ser utilizable efectivamente por el público, excepción hecha de los aparcamientos" (el autor se está refiriendo a la LOCM).
} 
La Ley andaluza resuelve estas cuestiones en su Art. 22. Según el tenor del precepto dentro de la superficie computable habría que incluir los espacios destinados a la exposición de mercancías a los que puedan acceder los consumidores para realizar compras, y los espacios internos destinados al tránsito de personas, realizándose el cómputo desde la puerta o acceso al establecimiento. Por el contrario, deben excluirse los destinados exclusivamente a almacén, aparcamiento, o a prestación de servicios. No se dice nada de los escaparates. Se excluyen, a su vez, en los establecimientos de carácter colectivo las zonas destinadas exclusivamente al tránsito común que no pertenezcan expresamente a ningún establecimiento (Art. 22.3).

b) Población del municipio en el que el establecimiento se va a implantar.

El elemento población está presente en la definición de "gran establecimiento"22. El Art. 23.1 de la Ley de Comercio de Andalucía a efectos de la exigencia de la licencia comercial autonómica, establece tres tipos de municipios en relación a los cuales se fijan correlativamente tres tamaños de establecimientos comerciales ${ }^{23}$ : los municipios de más de 25.000 habitantes, en los cuales se consideran grandes establecimientos los que tengan una superficie de $2.500 \mathrm{~m}^{2}$; los municipios con una población de entre 10.000 y 25.000 habitantes; y finalmente, para los municipios de menos de 10.000 habitantes $^{24}$.

La Ley del Comercio de Cantabria 1/2002 describe en su Art. 6.2 los espacios que deben incluirse dentro de la superficie útil de exposición y venta al público: "A los efectos de esta Ley, tendrá la consideración de superficie útil de exposición y ventas: la totalidad de los espacios donde se exponen las mercancías con carácter habitual y permanente, o destinados a tal fin con carácter eventual o periódico, y a los que puede acceder la clientela para realizar compras; los espacios internos destinados al tránsito de las personas; la superficie de la zona de cajas; la comprendida entre éstas y las puertas de salida, así como las dedicadas a actividades de prestación de servicios. En los establecimientos comerciales que dispongan de secciones de venta asistida por dependiente, asimismo, se considerará superficie útil de exposición y venta la zona ocupada por las personas vendedoras detrás del mostrador, a la cual no tiene acceso el público”.

22 Como ya hemos indicado, no ocurre así en algunas normas autonómicas, como la Ley 1/2002 de Cantabria, que siguiendo la pauta marcada por la LOCM estatal sólo utiliza el criterio de la superficie, con independencia por tanto de la población del municipio en que el establecimiento se pretende ubicar, para calificar a un "gran establecimiento comercial".

${ }^{23}$ La Ley 18/2005 de Equipamientos Comerciales de Cataluña distingue tres tipos de establecimientos comerciales: los "establecimientos comerciales", los "establecimientos comerciales medianos" y los "grandes establecimientos" (Vid. Arts. 3 y 4 ).

${ }^{24}$ Resulta curioso que la Ley canaria 10/2003 reguladora de la licencia comercial específica, a diferencia de otras normativas autonómicas, utilice la expresión "población de hecho" para re- 
Siguiendo la tendencia que se aprecia en las restantes normas autonómi$\operatorname{cas}^{25}$, el legislador andaluz ha ido reduciendo el tamaño de los establecimientos en relación a las dimensiones de los municipios, con lo cual se incrementa la intervención de la Comunidad Autónoma sobre la actividad comercial.

Hay un supuesto especial que recoge el mismo Art. 23.1, en el que no se tiene en cuenta el número de habitantes del municipio en donde se instale el establecimiento. Nos referimos a "los establecimientos comerciales que se dediquen exclusivamente a la venta de automóviles y otros vehículos, embarcaciones de recreo, maquinaria, materiales para la construcción, mobiliario, artículos de saneamiento, puertas y ventanas y, asimismo, los establecimientos de jardinería"; en estos casos, si superan los $2500 \mathrm{~m}^{2}$ se incluyen entre los denominados grandes establecimientos. Con esta previsión, la Ley andaluza sale al paso del problema que había suscitado la aplicación de la Ley de Comercio de 1996 a ciertos establecimientos peculiares, que aunque alcanzaban los 2500 $\mathrm{m}^{2}$ de superficie resultaba dudoso su encaje en el concepto legal diseñado por el legislador. Nos referimos a los establecimientos dedicados a la venta de un solo tipo de productos pero que requerían de grandes espacios para la exposición de sus artículos.

Ciertamente, el elemento "superficie" tiene una fuerza atractiva sobre otros aspectos definidores de los grandes establecimientos. $\mathrm{Y}$, aunque el legislador valora también otras circunstancias, termina volviendo al criterio de la extensión superficial para cerrar el concepto de "gran establecimiento comercial". Así lo demuestran los supuestos específicos que se aluden en el mismo Art. 23.2 ("No perderá la condición de gran establecimiento comercial el establecimiento individual que, teniendo una superficie útil para la exposición y venta al público que supere los límites establecidos en el apartado 1 del

ferirse a los municipios en los que se instalen los grandes establecimientos (Art. 3). Dicho concepto se definió posteriormente en el Decreto 235/2005, de 27 de diciembre, en los siguientes términos: “... se entiende por población de hecho la integrada por los vecinos que residen en un municipio determinado, según los últimos datos oficiales del padrón correspondiente, y por las personas no residentes que pernoctan en el mismo...".

${ }^{25}$ La ampliación de las modalidades de comercio minorista que son objeto de autorización y la reducción de la dimensión mínima exigida para someter la apertura de un establecimiento a autorización, a juicio de PALAU RAÍREZ, F, están provocando que la normativa reguladora de la apertura de grandes establecimientos comerciales está dejando de ser tal, para convertirse en una normativa general de apertura de establecimientos comerciales (Cfr. "La regulación de la apertura de establecimientos comerciales en la Unión Europea”. Madrid-Barcelona, 2003. Pág. 109). 
presente artículo, forme parte a su vez de un establecimiento comercial de carácter colectivo". El precepto se refiere al caso de la "gran superficie" dentro de un "gran establecimiento"). De igual modo el Art. 23.3, que a pesar de excluir de la consideración de grandes establecimientos comerciales a los mercados municipales de abastos, añade: "No obstante, si en el recinto del mercado hubiera un establecimiento individual cuya superficie útil para la exposición y venta al público supere los límites establecidos en el apartado 1 del presente artículo, dicho establecimiento será considerado, en sí mismo, un gran establecimiento comercial”.

\subsection{Destino del establecimiento: ejercicio del comercio al por menor}

Otra característica que posee el gran establecimiento comercial es la de ceñirse el ejercicio de la actividad comercial minorista. Lo dice muy claro el Art. 23 de la Ley que comentamos. En realidad, esta exigencia no es exclusiva del régimen de los grandes establecimientos, sino que resulta de la aplicación del propio concepto de establecimiento comercial recogido en el Art. 21. La actividad comercial de carácter mayorista no se somete por tanto al régimen de la autorización comercial autonómica ${ }^{26}$.

El concepto de comercio al por menor o minorista se concreta en el Art. 3 de la Ley 1/1996, mediante una definición positiva (Art. 2.1), a saber, "ejercicio profesional de la actividad de adquisición de productos para su reventa al consumidor final"; y una delimitación negativa o por exclusión (Art. 2.3). Así, quedan fuera del concepto tres supuestos de venta directa de determinados bienes realizada en el mismo lugar de su producción: a) La venta por fabricantes, dentro del propio recinto industrial, de los residuos y subproductos obtenidos en el proceso de producción; b) La venta directa por agricultores y ganaderos de productos agropecuarios en estado natural y en su lugar de producción, o en los centros cooperativos de recogida de tal producción; c) La venta realizada por los artesanos de sus productos en su propio taller.

En esta definición que ofrece la ley andaluza destaca como nota diferenciadora del tipo de actividad comercial realizada, la presencia en la venta del consumidor final (para el comercio minorista) o, por el contrario, de otro co-

\footnotetext{
${ }^{26}$ Cosa que no ocurre con el régimen de inscripción registral, obligatorio y común tanto para la actividad comercial de carácter mayorista como minorista (Vid. Art. 10), y con el régimen de apertura y cierre de los locales comerciales (Art. 15).
} 
merciante -minorista o mayorista- o empresario industrial o artesano (para la actividad comercial de carácter mayorista) ${ }^{27}$.

El ejercicio de la actividad comercial se ciñe a la "venta" o "reventa" de productos (literalmente "adquisición de productos para su reventa"), es decir, se refiere en todo caso al intercambio de bienes o productos. Con lo cual, si seguimos una interpretación literal del concepto, tendríamos que excluir de la actividad comercial a la prestación de servicios, que en numerosas ocasiones aparece estrechamente vinculada a la anterior o se ofrece conjuntamente con ella $^{28}$. Este criterio de exclusión puede resultar práctico a ciertos efectos, pero parece que no va en la línea de las últimas tendencias del desarrollo comercial, en las que la actividad comercial se ha vuelto progresivamente más compleja vinculándose a actividades culturales o de ocio, y asociándose a la oferta de determinados servicios ${ }^{29}$.

${ }^{27}$ El mismo criterio es el seguido por otras leyes autonómicas de comercio. Por ejemplo, la Ley 8/1989, de 5 de octubre, de la Actividad Comercial en Aragón, que en su Artículo 7.-1 establece: "Se entiende por actividad comercial de carácter mayorista el ejercicio habitual de adquisición de productos en nombre y por cuenta propios y su reventa a otros comerciantes mayoristas, minoristas o empresarios industriales o artesanos". (...) Artículo 8.-1: "Se entiende por actividad comercial de carácter minorista el ejercicio habitual de adquisición de productos en nombre y por cuenta propios para su reventa al consumidor final”.

${ }^{28}$ A diferencia de la Ley andaluza, en alguna norma autonómica, se alude expresamente a los servicios ofertados al público, o más exactamente a determinados servicios, como contenido de la actividad comercial. La cuestión puede tener relevancia al computar la superficie del establecimiento, ya que también habría que incluir en la misma los espacios destinados a la prestación de servicios. Por ejemplo, la Ley 9/1989, de 5 de octubre, de Ordenación de la Actividad Comercial en Aragón, aunque luego excluye del concepto determinados supuestos, define en su Art. 2.1 la actividad comercial como "la llevada a cabo por cuenta propia o ajena con la finalidad de poner a disposición de consumidores y usuarios bienes y servicios susceptibles del tráfico comercial"; o la Ley 16/2002, de 19 de diciembre, de Comercio de Castilla y León, cuyo Art. 2 determina: "1. A los efectos de la presente Ley se entiende por actividad comercial la que consiste en ofertar al mercado productos o mercancías con ánimo de lucro. Reglamentariamente se podrán establecer excepciones a lo señalado anteriormente. 2. También se considera actividad comercial la prestación de determinados servicios cuando se oferten al mercado con las características señaladas en el apartado anterior y deriven de la actividad comercial definida en el apartado $1^{\circ}$. Reglamentariamente se determinará la relación de servicios incluidos en el ámbito de aplicación de esta Ley”.

29 Por ejemplo, se considera un uso complementario de los grandes establecimientos el abastecimiento de combustible. Sobre la instalación de estaciones de servicio dentro de los grandes establecimientos comerciales, y sobre el derecho a incorporarlas sin que sean obstáculo las previsiones del planeamiento municipal, puede verse la Sentencia del Tribunal Superior de Justicia del País Vasco núm. 1045/2002, de 27 de noviembre. 


\subsection{Supuestos excluidos.}

Después de establecer un concepto positivo de gran establecimiento comercial, el legislador realiza una delimitación negativa excluyendo una serie de supuestos. Además de los comercios mayoristas, expresamente se excluyen del régimen de los grandes establecimientos los mercados municipales de abastos (Art. 23.3). También, las agrupaciones de comerciantes establecidas en el viario urbano con la finalidad de realizar en común actividades de promoción o cualquier otra forma de gestión del conjunto de establecimientos agrupados y de la zona comercial donde su ubican. Y ello, con independencia de la forma jurídica que dichas agrupaciones puedan adoptar.

\subsection{Los establecimientos de carácter colectivo}

No hemos de confundir el supuesto antes citado con el de los denominados "establecimientos de carácter colectivo", que si superan la superficie indicada en el Art. 23 también quedan sometidos al régimen de licencia comercial. En este caso, los establecimientos (que aparecen conformados por un conjunto de establecimientos comerciales individuales integrados en un edificio o complejo de edificios, en los que se ejerzan las respectivas actividades de forma empresarialmente independiente), comparten la utilización de elementos comunes, que la ley enumera: acceso desde la vía pública de uso exclusivo o preferente de los establecimientos o sus clientes; aparcamientos privados; servicios para los clientes; imagen comercial común; perímetro común delimitado (Art. 21.2). Ésta será precisamente su nota identificativa, la presencia de elementos comunes. Es más, según la dicción literal del precepto ${ }^{30}$, bastaría con uno sólo de ellos para considerar al conjunto como establecimiento de carácter colectivo.

La Ley de Comercio Interior de Andalucía, en su versión de 1996, incluía dentro de las grandes superficies a los centros comerciales ${ }^{31}$. En el texto del

30 “... siempre que compartan la utilización de algunos de los siguientes elementos...” (Art. 21.2).

${ }^{31}$ Los centros comerciales se definían como el conjunto de establecimientos comerciales que, integrados en un edificio o complejo de edificios, ejercen las respectivas actividades de forma empresarialmente independiente, disponiendo de determinados elementos de gestión comunes.

En la Ley estatal de Comercio Minorista este tipo de establecimientos quedaba excluido del régimen de licencia comercial, ya que tanto desde el punto de vista jurídico-mercantil como jurídico-administrativo los centros comerciales no constituyen un solo establecimiento sino un conjunto de establecimientos diferentes, de diferente titularidad.

Los centros comerciales constituyen un tipo de establecimiento comercial que ha proliferado enormemente en los últimos años, localizándose no ya en las periferias urbanas, sino incluso en 
año 2002, desaparece esta última expresión. El legislador la sustituye por la de "establecimientos de carácter colectivo", quizá con la finalidad de incluir supuestos que no encajaban en sentido estricto dentro de lo que entendemos por "centro comercial". Ha preferido recoger lo sustancial del concepto y calificarlos genéricamente como establecimientos de carácter colectivo, en lugar de aludir a denominaciones más específicas que pueden variar ${ }^{32}$.

\subsection{Regímenes específicos: los establecimientos de descuento o de venta de restos de fábrica}

Otra de las novedades de la reforma introducida en el año 2002 por el legislador andaluz, es la del sometimiento a autorización específica a los establecimientos de descuento y de venta de restos de fábrica. La Ley los asimila a los grandes establecimientos comerciales a efectos de la exigencia de previa licencia, aunque luego establece algunas especificidades en el procedimiento para su otorgamiento.

Tales establecimientos se definen positivamente de acuerdo con el tipo de actividad comercial que desarrollan en los artículos 24 (establecimientos de descuento ${ }^{33}$ ) y 82 (establecimientos de venta de restos de fábrica ${ }^{34}$ ). Sin

los centros históricos como elemento revitalizador de una nueva forma de comercio intraurbano y del turismo.

${ }^{32}$ Las denominaciones de los establecimientos comerciales de carácter colectivo que recogen las normas autonómicas sobre comercio interior son ciertamente heterogéneas. Baste poner algunos ejemplos: "recinto comercial" (Art. 11.2 del Plan de Ordenación de Equipamientos Comerciales en Gran Superficie de la Comunidad Autónoma de Aragón de 2005); la "concentración comercial” (Art. 2.4.c) de la Ley 18/2005 de Equipamientos Comerciales de Cataluña); "Parques comerciales" (Art. 17.2 Ley 16/1999, de 29 de abril, de comercio interior de la Comunidad de Madrid); "polígono comercial” (Art. 16 de la Ley Foral 17/2001, de 12 de julio, reguladora del comercio en Navarra).

33 “... se consideran establecimientos de descuento aquellos que, ofreciendo en régimen de autoservicio productos de alimentación y, en su caso, otros productos de uso cotidiano, con una alta rotación y consumo generalizado, funcionen bajo un mismo nombre comercial, pertenezcan a una misma empresa o grupo de empresas y reúnan, al menos, tres de las siguientes características: a) Que se promocionen con el carácter de establecimiento de descuento; b) Que el número de referencias en la oferta total del establecimiento sea inferior a mil; c) Que más del cincuenta por ciento de los artículos ofertados se expongan en el propio soporte de transporte; d) Que el número de marcas blancas propias o del distribuidor, integrado en el surtido a comercializar, supere en un cuarenta por ciento al número de marcas de fabricante ofertadas en el establecimiento; e) Que no exista venta asistida, con excepción de en la línea de cajas".

34 " 1 . Se consideran establecimientos de venta de restos de fábrica aquellos que se dediquen exclusivamente a la venta directa y permanente por el fabricante, bien por sí mismo o a través de 
embargo, el concepto se completa, de nuevo, con una referencia a la extensión de la superficie del establecimiento. Si cuentan con una superficie igual o superior a $400 \mathrm{~m}^{2}$, se someten a un procedimiento especial definido en el Capítulo II del Título IV de la Ley. En caso de que superen los límites de extensión superficial establecidos para los grandes establecimientos se someterán al mismo régimen que estos últimos.

\section{LA LICENCIA COMERCIAL ESPECÍFICA PARA LA INSTALA- CIÓN, APERTURA Y TRASLADO DE GRANDES ESTABLECI- MIENTOS COMERCIALES. LA DENOMINADA SEGUNDA LI- CENCIA}

Como es sabido, la reforma operada en el año 2002 sobre la Ley de Comercio de Andalucía sustituye la intervención de la Comunidad Autónoma sobre las grandes superficies a través del "informe comercial" por una "licencia comercial específica", denominada convencionalmente "segunda licencia". Dicha licencia se exige con carácter previo a la instalación de los grandes establecimientos comerciales, así como los traslados, las ampliaciones de la superficie útil para la exposición y venta al público, y los cambios de actividad.

La modificación introducida por el legislador supone sobre todo un cambio en la forma de intervención (de informe a autorización, de acto de trámite a acto principal y resolutorio), en el procedimiento (de procedimiento tramitado en sede municipal a procedimiento específico instruido por los órganos autonómicos) y en el momento de la intervención (antes con ocasión de la obtención de la licencia municipal, ahora con carácter previo a la licencia de apertura). Desde el punto de vista sustantivo la Comunidad Autónoma ya estaba realizando un control, a través del informe comercial que tenía carácter vinculante, aunque es cierto que ahora dicho control al instrumentarse a través de una autorización específica adquiere mayor complitud.

La licencia comercial específica resulta preceptiva para poder instalar, trasladar, ampliar o cambiar la actividad de un gran establecimiento comercial. Se trata de una licencia que tiene carácter previo a la licencia municipal de apertura. El legislador lo proclama con cierta contundencia. De forma muy nítida el Art. 26.1 determina que "no podrá tramitarse solicitud de licencia

comerciante minorista que venda o distribuya su marca, de productos que respondan a la definición y requisitos de los artículos 79 y 80.2 de la presente Ley, con excepción de los productos de alimentación". 
municipal alguna sin haberse otorgado previamente la licencia comercial preceptiva de la Consejería competente en materia de comercio interior debiendo aportarse la misma junto a la solicitud de la licencia municipal que corresponda" 35 . Además, ese mismo precepto establece la sanción de nulidad para las licencias municipales otorgadas sin disponer previamente de la licencia autonómica, y de las licencias municipales que se otorguen en contra de las determinaciones de aquéllas. Por último, para asegurar el cumplimiento efectivo de la norma, el Art. 93 tipifica como infracción muy grave el inicio de actuaciones sin que se haya obtenido previamente la correspondiente licencia comercial (por cierto, el precepto no aclara qué ha de entenderse por "actuaciones" ni tampoco en qué consiste su "inicio"). La sanción que acompaña a este tipo de infracción se determina en el Art. 95.1 c), a saber, multa desde 30.001 hasta 150.000 euros, cantidad que se podrá sobrepasar hasta alcanzar su décuplo. Es decir, es la máxima que puede imponerse con arreglo a la ley.

\subsection{Las actividades sujetas a licencia comercial ${ }^{36}$.}

Los supuestos de exigencia de licencia comercial específica se determinan en los artículos 28 y 29 de la Ley, distinguiéndose los grandes establecimientos de los establecimientos de descuento y de venta de restos de fábrica.

Para los primeros, son cuatro las actividades que requieren la obtención de licencia comercial previa: la instalación ${ }^{37}$, el traslado del estable-

${ }^{35}$ Por su parte el Art. 25.2, en su párrafo segundo establece que no podrán llevarse a cabo actos de transformación física del suelo, ni de desarrollo de actividad que impliquen uso del suelo en orden a la instalación, traslado, ampliación de la superficie útil para la exposición y venta al público o cambio de actividad de los grandes establecimientos comerciales, o en orden a la instalación de los establecimientos de descuento y de venta de restos de fábrica, sin haber obtenido previamente la preceptiva licencia comercial, que deberá otorgarse antes de la solicitud de las correspondientes licencias municipales.

${ }^{36}$ Sobre el tema Vid. NOGUERA DE LA MUELA, B. "El régimen jurídico de los grandes establecimientos en Cataluña”. R.A.A.P. no 44/2001. Págs. 89 y ss.

${ }^{37}$ La Ley utiliza la expresión "instalación", quizás, para distinguir la licencia comercial de la conocida licencia municipal de apertura, pero dentro de este término parece lógico que habría que incluir tanto los proyectos de nueva construcción como las transformaciones de inmuebles preexistentes, es decir los casos de reapertura de antiguos comercios que anteriormente no estaban sometidos al régimen de licencia comercial, pero que ahora sí quedan dentro de su ámbito de aplicación (Cfr. PÉREZ FERNÁNDEZ, J. M. "Urbanismo comercial y libertad de empresa". Madrid 1998; y NOGUERA DE LA MUELA, B. "El régimen jurídico de los grandes establecimientos en Cataluña”. R.A.A.P. no 44/2001. Págs. 89 y ss.). 
cimiento $^{38}$, la ampliación de superficie útil de exposición y venta al público, y el cambio de actividad ${ }^{39}$.

En relación a los establecimientos de descuento y de venta de restos de fábrica, la ley sólo exige la obtención de la previa licencia comercial para la instalación del establecimiento, pero no dice nada del traslado, ampliación de superficie o cambio de actividad. Ese es el tenor literal del Art. 29 y del Art. 25.2 párrafo segundo. Sin embargo, en una interpretación conjunta de los preceptos legales y dado que la Ley asimila estos establecimientos al régimen de los "grandes", cabría entender que también habría que exigir la licencia para los supuestos de traslado del establecimiento, ampliación de la superficie (cuando como consecuencia de dicha ampliación se superen los límites establecidos para los grandes establecimientos) y finalmente, para el cambio de actividad (en este caso también sería lógico exigirla puesto que los establecimientos de descuento y de venta de restos de fábrica se caracterizan por realizar un tipo concreto de actividad comercial definida expresamente por el legislador).

38 Parece también lógico que si el ejercicio del comercio se realiza in situ, dentro del establecimiento comercial, el cambio de ubicación quede sometido al mismo régimen de autorización que el de la instalación y apertura.

${ }^{39}$ En este caso, la Ley no define qué deba entenderse por "cambio de actividad". Cabe interpretar que se trata de un cambio o variación en la actividad comercial que se desarrolla (por ejemplo, antiguo hipermercado que se transforma en centro comercial). Pueden producirse cambios menores (tipo de productos que se ofrecen al mercado) que no necesiten de una nueva licencia. El paso del comercio mayorista a minorista también exigiría licencia comercial específica, aunque no el proceso inverso, ya que la actividad comercial mayorista queda fuera del ámbito de la Ley. De todos modos, las operaciones de cambio de actividad deberían quizás someterse a un procedimiento más simplificado que el exigido para las nuevas instalaciones.

El 31 de julio de 2007 ha aparecido en el BOJA, el Decreto 208/2007, de 17 de julio, por el que se aprueba el Plan Andaluz de Orientación Comercial 2007-2010 y se regulan los criterios de evaluación para el otorgamiento de licencia comercial de grandes establecimientos comerciales. En su Art. 2, que determina el ámbito de aplicación de la norma se hace referencia a: a) La primera instalación de los grandes establecimientos comerciales definidos en el Art. 23 de la Ley 1/1996, de 10 de enero; b) El traslado, total o parcial, de las instalaciones de los grandes establecimientos comerciales; c) Las ampliaciones de la superficie útil para la exposición y venta al público de los grandes establecimientos comerciales, de los establecimientos comerciales que no tengan dicha consideración, cuando la ampliación propuesta implique la superación de los límites establecidos en el artículo 23.1 de la Ley 1/1996, de 10 de enero; d) Los cambios de actividad de los grandes establecimientos comerciales, sin que conlleve un incremento de volumen de la edificación, cuando suponga una incorporación nueva de la superficie útil para la exposición y venta al público, dedicada al comercio mayorista, ocio, servicios o cualquiera otra finalidad; o cuando conlleven una alteración de la tipología comercial. 
El legislador contempla en su Art. 25.3 otras dos operaciones, que aunque no se someten a la licencia comercial específica, sí requieren la autorización de la Junta de Andalucía. Se trata de "la transmisión" o cambio de titularidad del gran establecimiento $^{40}$, y de la transmisión de la licencia comercial ya obtenida (Art. 25.3 segundo párrafo $)^{41}$. En ambos casos, deberá emitirse previamente informe del órgano competente en materia de defensa de la competencia. La Ley excluye de la obligación de solicitar autorización a las transmisiones hereditarias.

\subsection{El traslado del procedimiento para el otorgamiento de la licencia comer- cial del ámbito municipal al autonómico}

El legislador andaluz optó en el año 1996 por encauzar el control de la Comunidad Autónoma sobre la implantación de las grandes superficies a través de un informe preceptivo y vinculante que se insertaba, dentro del procedimiento de otorgamiento de la licencia municipal de apertura ${ }^{42}$. Con la aprobación de la Ley 6/2002 el sistema se cambió por el de licencia comercial específica.

Las causas que motivaron esta decisión no se explicitan en el texto de la nueva ley ${ }^{43}$. Probablemente fueron razones de tipo práctico, que tienen que

40 “... o de las acciones y participaciones de las sociedades que, directa o indirectamente, sean sus titulares y estén obligadas a consolidar sus cuentas, de acuerdo con los artículos 42 y siguientes del Código de Comercio y 185 del Texto Refundido de la Ley de Sociedades Anónimas, aprobado por Real Decreto Legislativo 1564/1989, de 22 de diciembre" (Art. 25.3).

${ }^{41}$ Es lógica esta exigencia ya que no es indiferente para el legislador quién realice la actividad comercial autorizada. Ha de tratarse de una persona física o jurídica, comerciante, previamente inscrita en el Registro de comerciantes y actividades comerciales de Andalucía (Art. 10.2). Además, la norma exige en el promotor-solicitante unas condiciones determinadas de solvencia económica y financiera (vid. Art. 36.1 que señala la documentación que debe aportar al solicitar la licencia comercial). Desde la óptica de la defensa de la competencia, también interesa conocer quién es el titular de la empresa o grupo de empresas a las que se va a traspasar el gran establecimiento.

${ }^{42}$ El sistema de intervención elegido por la Ley de Comercio andaluza se justificaba en la propia EM de la Ley 1/1996 (epígrafe IV) en la aplicación del principio de economía procedimental consagrado en el Art. 39 de la vieja Ley de Procedimiento Administrativo.

El informe comercial no era el único requerido por la norma autonómica para autorizar la nueva implantación. También debían emitirse el Informe Ambiental y el Informe sobre la incidencia de la gran superficie en la Ordenación del Territorio, previstos en la Ley 1/1994, de 11 de enero, de Ordenación del Territorio de la Comunidad Autónoma de Andalucía y en la Ley 7/1994 de 18 de mayo, de Protección Ambiental.

${ }^{43}$ El Preámbulo sólo indica que introduce la reforma "en línea con la legislación establecida al respecto por otras Comunidades Autónomas" ( $\mathrm{n}^{\mathrm{o}}$ 2). 
ver con la eficacia administrativa. Al emitirse el informe comercial casi al final de la tramitación del procedimiento municipal de apertura, la intervención de la Comunidad Autónoma resultaba tardía y quedaba muy condicionada en la práctica por las actuaciones previas tanto de los promotores del gran establecimiento (por ejemplo, gestión de suelo) como de la Administración municipal (que ya había instruido la solicitud de licencia municipal y cuyo procedimiento como decimos estaba ya avanzado) ${ }^{44}$. Con todo, el traslado del procedimiento y la configuración de la segunda licencia previsto en la Ley de 2002, parece que chocan con la idea de la ventanilla única y de simplificación de los procedimientos que viene exigiendo la normativa comunitaria.

El procedimiento para el otorgamiento de la licencia comercial autonómica responde en la actualidad al siguiente esquema:

1. Solicitudes, documentación y subsanación.

- Presentación de solicitud por parte del promotor o promotores de un gran establecimiento ante la Consejería competente en materia de comercio interior (en la actualidad Turismo, Comercio y Deporte), acompañada de la documentación establecida en el Art. 36.1 de la Ley $6 / 2002^{45}$.

${ }^{44}$ Dentro del procedimiento previsto en los artículos 22 al 25 de la Ley de Comercio Interior de Andalucía (texto de 1996), una vez recibidos en el Ayuntamiento el Informe ambiental y el Informe sobre la posible incidencia de la gran superficie en la Ordenación del Territorio, por supuesto siempre que dichos informes fueran favorables, y una vez instruida por los servicios municipales la solicitud de licencia de apertura, ésta debía remitirse a la Consejería competente en materia de comercio interior para su informe preceptivo.

${ }^{45}$ El Art. 36 fue modificado por la Ley 13/2005, de 11 de noviembre, de Medidas para la Vivienda Protegida y el Suelo.

Llama la atención el detalle con que la Ley regula la documentación requerida para solicitar la licencia comercial. La exigencia de solvencia económica y financiera al promotor recuerda a los requisitos establecidos en la Ley de Contratos para ser contratista.

En relación a la documentación exigida en las leyes autonómicas para solicitar la licencia comercial, puede verse la Sentencia del Tribunal de Justicia de Cantabria núm. 83/2006, de 6 de marzo, que declara la nulidad de diversos preceptos del Decreto cántabro 60/2004, de 17 de junio, relativos a las solicitudes de licencia comercial específica. El Tribunal considera que el citado Decreto, que desarrolla la Ley 1/2002, de 26 de febrero, del Comercio de Cantabria, se extralimita al exigir en el procedimiento para la concesión de la licencia comercial, una documentación no prevista en la Ley. En concreto: "... el plan de expansión de la empresa y las cuentas de explotación previstas para los cinco primeros años de funcionamiento" (Art. 24.1.3 párrafo VI in fine), y "la relación y emplazamiento de los establecimientos comerciales de la empresa solicitante 
2. Tramitación (Art. 37) ${ }^{46}$.

- Trámite de Información Pública.

- Informes preceptivos: (son cinco los informes previstos, salvo el informe en materia de Defensa de la competencia, los demás son vinculantes en caso de resultar desfavorables).

a) Informe de la Consejería competente en materia de urbanismo. Contenido: adecuación del proyecto a la legalidad urbanística. Plazo máximo de emisión: dos meses.

b) Informe de la Consejería competente en materia de Ordenación del Territorio (Previsto en el Art. 30 de la LOTA). Contenido: incidencia del proyecto en la Ordenación del Territorio. Plazo: dos meses.

c) Informe de la Consejería competente en materia de medio ambiente. Contenido: incidencia del proyecto en el medio ambiente. Informe ambiental.

d) Informe del municipio o municipios donde se pretende implantar la actuación. Órgano competente: Pleno. Contenido: idoneidad del proyecto en relación a: la saturación del sistema viario por el incremento de desplazamientos, la accesibilidad, aparcamientos y las garantías de adecuación de las infraestructuras de abastecimiento y saneamiento de aguas, así como las de suministro de energía eléctrica. Plazo: dos meses. Exigencia de acuerdo motivado.

e) Informe del órgano competente en materia de Defensa de la competencia (preceptivo y no vinculante).

- Audiencia a las organizaciones de consumidores, sindicales y empresariales más representativas, y respectiva Cámara Oficial de Comercio, Industria y, en su caso Navegación.

ubicados en el territorio de la Comunidad Autónoma de Cantabria, con indicación de la enseña o enseñas utilizadas, y su superficie de venta total y desglosada según el tipo de productos que se comercializan" (Art. 24.1.3, párrafo XI). Asimismo, la Sentencia declara nula la Disposición Final $1^{1}$ - del citado Decreto, en virtud de la cual se faculta al consejero de Economía y Hacienda para modificar mediante Orden la documentación precisa para la concesión de la licencia comercial específica, así como para dictar las normas necesarias en aplicación y desarrollo de lo establecido en el Decreto.

46 También este precepto ha sido objeto de modificación operada por la citada Ley 13/2005, de 11 de noviembre, de Medidas para la Vivienda Protegida y el Suelo. La modificación introducida afecta sobre todo al orden en que deben realizarse las diferentes actuaciones dentro del procedimiento de otorgamiento. Anteriormente el trámite de información pública se situaba en un momento posterior a la emisión del informe en materia de defensa de la competencia, ordenación del territorio e informe municipal. Después de la información pública debía procederse a la emisión del informe ambiental. 
- Consulta a la Comisión Asesora de Comercio Interior de Andalucía.

- Audiencia al interesado (Art. 39).

3. Resolución (Art. 40).

- Consejero de Turismo, Comercio y Deporte (competente en materia de comercio interior).

- Plazo máximo para resolver y notificar: seis meses.

- Silencio administrativo: efectos estimatorios.

- Contenido: Autorizar la actividad solicitada. Plazo de iniciación de la actividad: no inferior a un año (a partir de la resolución expresa) y como máximo de 2 años en caso de silencio. Licencia condicionada, pérdida de efectos en caso de no iniciarse la actividad ${ }^{47}$.

\subsection{La participación del Ayuntamiento en el procedimiento de otorgamiento de la licencia autonómica}

A la vista de la regulación establecida se puede afirmar que son tres los momentos en que el Ayuntamiento puede intervenir en el procedimiento para el otorgamiento de la licencia comercial autonómica. La Ley andaluza ha querido dar un protagonismo lógico al municipio en cuyo territorio se va a instalar el gran establecimiento ${ }^{48}$. Posteriormente, en caso de que se otorgue la licencia autonómica, el Ayuntamiento también podrá llevar a cabo un control sobre la nueva implantación a través de la licencia municipal de apertura. Veamos qué momentos son estos.

En primer lugar, el Ayuntamiento podrá emitir cédula urbanística municipal que el promotor del gran establecimiento deberá acompañar al solicitar

\footnotetext{
${ }^{47}$ La Ley establece un plazo para que se inicie la actividad comercial autorizada y prevé un régimen de extinción de la licencia o de pérdida de efectos. El plazo, que deberá concretar la resolución, puede variar dependiendo de la solicitud y características del proyecto, pero en todo caso no será inferior al año, si la resolución es expresa, o a los dos años si se considera estimada la solicitud por silencio administrativo. Los efectos del incumplimiento del plazo son claros: la pérdida de efectos de la licencia. Eso sí, siempre que no se hubiera iniciado la actividad por causas imputables al interesado. Parece lógico, teniendo en cuenta que una vez obtenida la licencia comercial, el promotor del gran establecimiento debe construir la nueva instalación solicitando previamente las oportunas licencias municipales.

${ }^{48}$ Hablamos de Ayuntamiento en singular, pero el Art. 37 se refiere al "municipio o municipios donde se pretenda implantar la actuación...".
} 
la licencia comercial ante la Junta de Andalucía ${ }^{49}$. A través de la cédula el Ayuntamiento podrá pronunciarse sobre la compatibilidad del proyecto con los usos del suelo establecidos en el planeamiento municipal ${ }^{50}$.

En segundo lugar, dentro ya de la fase de instrucción del procedimiento autorizatorio, a través del informe municipal previsto en el Art. $37.1 \mathrm{~d}$ ). El contenido de dicho informe, que corresponde emitir al Pleno, se especifica en el Art. 37. 1. d) de la Ley ${ }^{51}$. Este artículo tiene un carácter indicativo, no se trata de una norma cerrada, por lo que en principio, el Ayuntamiento podría pronunciarse sobre otros extremos no previstos expresamente en la Ley de Comercio, pero que estuvieran relacionados con las competencias municipales. El citado informe tiene carácter vinculante en caso de ser desfavorable, con lo cual, en teoría, el Ayuntamiento podría oponerse a la apertura del nuevo establecimiento e impedir con ello el otorgamiento de la licencia autonómica, eso sí, siempre mediante acuerdo motivado. De todos modos, esto no suele ocurrir en la práctica. Para el caso de que el Ayuntamiento establezca condiciones de algún tipo, por ejemplo, mejora de los accesos, número de aparcamientos, etc. lo lógico es que tales previsiones se trasladen al contenido de la licencia comercial específica a fin de que se ejecuten por el promotor. En caso contrario, no tiene mucho sentido realizar la consulta al Ayuntamiento implicado.

Si el Ayuntamiento emite informe favorable parece lógico que también luego conceda las correspondientes licencias municipales. Lo que en ningún

\footnotetext{
${ }^{49}$ Inicialmente, la Ley de Comercio andaluza exigía la presentación de "certificación del Ayuntamiento en cuyo municipio se pretenda la actuación, sobre la adecuación de la instalación proyectada a las determinaciones que, respecto a los usos del suelo afectado, se contienen en el planeamiento urbanístico vigente...", pero el Art. 36 fue modificado en este punto por la Ley 13/2005, de 11 de noviembre, de Medidas para la Vivienda Protegida y el Suelo.

${ }^{50}$ La conexión existente entre planeamiento urbanístico y los grandes establecimientos, de la que luego hablaremos, se refleja en la Disposición Adicional Segunda de la Ley de Comercio Interior de Andalucía, introducida por la Ley 13/2005, de 11 de noviembre, de Medidas para la Vivienda Protegida y el Suelo y modificada a su vez por la Ley 1/2006, de 16 de mayo.

${ }^{51} \mathrm{El}$ informe "versará sobre la idoneidad del proyecto y, expresamente, sobre la saturación del sistema viario por el incremento de desplazamientos, la accesibilidad, aparcamientos y las garantías de adecuación de las infraestructuras de abastecimiento y saneamiento de aguas, así como las de suministro de energía eléctrica" (Art. 37.1.d).

La atribución de la competencia al Pleno puede resultar lógica en determinados Ayuntamientos, pero quizás resulte excesiva en otros casos, como por ejemplo grandes municipios.
} 
caso puede condicionar el otorgamiento futuro de las licencias municipales es la concesión de la autorización comercial por la Junta de Andalucía. El Art. 26.3 lo dice claramente: "la concesión de la previa licencia comercial por la Consejería competente no obligará a los Ayuntamientos a otorgar las licencias que correspondan dentro del ámbito de su competencia, que deberán ajustarse a las demás determinaciones de la normativa de aplicación”.

Por último, el Ayuntamiento también puede participar en el procedimiento de otorgamiento de la licencia comercial a través de su presencia en la Comisión Asesora de Comercio Interior de Andalucía ${ }^{52}$.

\subsection{Comisión Asesora de Comercio Interior de Andalucía}

El último trámite previsto por el Art. 37, antes de dar audiencia al interesado, es la realización de una consulta, que tiene carácter preceptivo aunque no vinculante, a la Comisión Asesora de Comercio Interior de Andalucía.

Como su nombre indica, la citada Comisión se constituye como órgano de carácter consultivo de la Consejería en materia de comercio interior. Su composición es mixta, y sus integrantes representan los distintos intereses afectados en el sector.

Además de intervenir en los procedimientos de elaboración de disposiciones generales y planes relacionados con la materia, la Ley ordena expresamente que se le dé audiencia en los procedimientos de concesión de licencias comerciales para los grandes establecimientos. También prevé que a la reunión de la Comisión celebrada a tal efecto, podrán asistir, con voz pero sin voto los representantes de los Ayuntamientos afectados ${ }^{53}$.

La participación de Comisiones de carácter representativo en los procedimientos de otorgamiento de licencia de grandes establecimientos ha sido nota común en las diferentes leyes autonómicas sobre comercio interior. La composición plural de estos órganos ha sido acogida favorablemente en cuanto garantizadora del principio de participación. Sin embargo, también ha sus-

\footnotetext{
52 Bien sea por medio de los representantes de los municipios de Andalucía, que forman parte de este órgano consultivo (Art. 13.1.h), o en calidad de Ayuntamiento afectado.

53 Por ejemplo, Ayuntamientos vecinos. Este supuesto no será infrecuente si tenemos en cuenta la incidencia de este tipo de establecimientos en el área metropolitana.
} 
citado algún recelo, en cuanto las mismas puedan asegurar la adopción de una decisión objetiva y neutral. No es difícil imaginar las presiones a que se verán sometidos los miembros de dichas Comisiones dados los fuertes intereses afectados por sus decisiones ${ }^{54}$.

\subsection{Examen de los criterios establecidos para la adjudicación: discrecionali- dad y conceptos jurídicos indeterminados. Las medidas correctoras}

El Art. 38 de la Ley establece los criterios, parámetros o pautas que la Consejería competente debe valorar al otorgar o denegar la licencia comercial autonómica. Se trata de un precepto clave, que requiere una correcta interpretación y aplicación.

Lo primero que hace el legislador es fijar el marco principal de referencia dentro del cual debe encajarse la autorización que en su caso se concede. Este marco no es otro que el Plan Andaluz de Orientación Comercial. Según establece el citado Art. 38, el otorgamiento o denegación de la licencia comercial deberá acordarse teniendo en cuenta su adecuación al Plan Andaluz de Orientación Comercial. Se produce, pues, una remisión legal al contenido de un plan futuro que deberá aprobarse mediante Decreto del Consejo de Gobierno ${ }^{55}$.

${ }^{54}$ El Tribunal Constitucional en STC 227/1993 señaló en relación a una Comisión de este tipo que "la composición plural de esta Comisión garantiza la representación de los distintos intereses sectoriales que concurren en el tema y que la ley trata de cohonestar, alejando la sospecha de una decisión arbitraria o graciosa”.

${ }^{55}$ En la fecha en que se cierran estas páginas se ha publicado en el BOJA del 31 de julio de 2007, el Decreto 208/2007, de 17 de julio, por el que se aprueba el Plan Andaluz de Orientación Comercial 2007-2010 y se regulan los criterios de evaluación para el otorgamiento de licencia comercial de grandes establecimientos comerciales.

En la citada norma, que no se limita a aprobar el segundo plan cuatrienal de orientación comercial para Andalucía, sino que regula también los criterios de valoración y los sistemas de evaluación de las solicitudes de licencia comercial de grandes establecimientos comerciales, se establecen una larga lista de principios informadores "que han de inspirar a la Consejería competente en materia de comercio interior, en materia de evaluación y autorización de grandes establecimientos comerciales" (EM del Decreto 208/2007). Dichos principios, que quizás en sentido lógico deberían incluirse en la propia Ley de Comercio, son los siguientes: a) El equilibrio de la oferta y la demanda comercial con el objetivo de favorecer la convivencia de todas las formas comerciales; b) La adecuada ubicación territorial de los establecimientos comerciales; c) La integración de los grandes establecimientos comerciales en la estructura urbana y de transporte existente, favoreciendo la accesibilidad, su acceso a los consumidores y minimizando o mejorando el impacto que su funcionamiento ocasione en la movilidad; d) La reducción de los desplazamientos de la población en la compra de productos de consumo cotidiano; e) El crecimiento equilibrado y gra- 
A continuación la norma añade una serie de criterios de ponderación ${ }^{56}$ :

a) La existencia, o no, de un equipamiento comercial adecuado en la zona afectada por el nuevo emplazamiento que garantice a la población una oferta de artículos en condiciones de calidad, variedad, servicio y precios, así como la libre competencia entre empresas que evite situaciones de dominio de mercado en sus respectivas áreas de influencia.

b) La integración del establecimiento en la estructura comercial existente, mediante la valoración de las medidas adoptadas por el promotor en orden a corregir, en su caso, el impacto que la instalación pudiera ocasionar al comercio previamente establecido en la zona de influencia, fundamentalmente respecto a los pequeños y medianos establecimientos comerciales, por medio de actuaciones de común interés para la zona.

dual de la estructura comercial, evitando un crecimiento súbito y desproporcionado de la oferta comercial; f) La modernización progresiva y armónica del pequeño y mediano comercio mediante su especialización; g) El mantenimiento y la creación de empleo de calidad en el sector del comercio; h) La igualdad de oportunidades entre mujeres y hombres conforme a lo recogido en la Ley orgánica 3/2007, de 22 de marzo, para la igualdad efectiva de mujeres y hombres; i) La promoción de la libre competencia, evitando situaciones monopolísticas o de dominio de mercado; j) La promoción de los derechos de la población consumidora y usuaria; k) El establecimiento de sistemas de aseguramiento de la calidad ambiental de los grandes establecimientos comerciales; 1) La eficiencia tecnológica, dirigida a minimizar el consumo de los recursos.

${ }^{56}$ Tanto la Ley estatal de Ordenación del Comercio Minorista (LOCM) como las leyes autonómicas de comercio han fijado también parámetros de valoración. En muchos casos estos criterios resultan muy amplios y de interpretación compleja.

La LOCM establece, con carácter de norma básica, dos criterios a tener en cuenta: la existencia, o no, de un equipamiento comercial adecuado en la zona afectada por el nuevo emplazamiento; y los efectos que éste pudiera ejercer sobre la estructura comercial de aquella (Art. 6.2). A continuación define cada uno de estos dos conceptos, ya sin el carácter de normas básicas.

Por su parte, las diferentes normas autonómicas aluden a aspectos tales como el ajuste a la normativa urbanística; las condiciones de accesibilidad del establecimiento (transporte colectivo, etc.); las cargas específicas para la colectividad determinadas reglamentariamente; los efectos sobre el nivel de ocupación de la zona; la tutela y ayuda a la pequeña y mediana empresa; el nivel adecuado de equipamiento comercial en el que se garanticen la armonización de los intereses de los grandes, medianos y pequeños comerciantes; la libertad de competencia dentro de la defensa de la pequeña y mediana empresa; etc.

Antes de la reforma operada por la Ley 6/2002, el Art. 23.2 de la Ley andaluza marcaba cuatro criterios de valoración: a) La integración de la gran superficie en el tejido comercial de los núcleos de población existentes dentro de su ámbito de influencia y, en particular su incidencia sobre: 1. La racionalización de la distribución comercial; 2. La mejora de las estructuras comerciales existentes y de la productividad del sector; 3. La renovación ordenada y progresiva de los equipamientos comerciales. b) La protección y defensa de los intereses de los consumidores. 
c) La localización del establecimiento en cuanto a su entorno comercial.

d) La incidencia de la nueva instalación en el sistema viario, la dotación de plazas de aparcamiento y la accesibilidad del establecimiento proyectado.

e) La contribución del proyecto al mantenimiento o a la expansión del nivel de ocupación laboral en el área de influencia.

Del examen de estos criterios podemos deducir que estamos ante una licencia de carácter discrecional ${ }^{57}$. La Administración cuenta con un amplio abanico de datos a ponderar, difícilmente medibles. Algunos resultan más objetivables que otros (dotación de plazas de aparcamiento, accesibilidad del establecimiento proyectado). Aparecen numerosos conceptos jurídicos indeterminados de difícil interpretación (impacto sobre el comercio previamente establecido en la zona de influencia, existencia de equipamiento adecuado) ${ }^{58}$, objetivos de política comercial (libre competencia entre empresas que evite situaciones de dominio de mercado, contribución del proyecto al mantenimiento o a la expansión del nivel de ocupación laboral), criterios de oportunidad.

${ }^{57}$ En la Sentencia del Tribunal Superior de Justicia de Murcia núm. 200/2003, de 6 de junio, se hace referencia expresa a la existencia de una "potestad discrecional para conceder o no licencias comerciales específicas". En este caso, el Tribunal consideró procedente la denegación por la Comunidad Autónoma de una licencia comercial, por considerar que el proyecto de la nueva implantación comercial estaba sobredimensionado porque no existía suficiente hueco de mercado en la zona afectada para un gran establecimiento comercial.

${ }^{58}$ Sobre el concepto de "equipamiento comercial adecuado" se pronuncia la Sentencia del Tribunal Superior de Justicia del País Vasco núm. 681/2002, de 1 de julio, en relación al Art. 5 del Decreto 58/2001, de 27 de marzo, del Gobierno Vasco, sobre implantación, modificación y ampliación de grandes establecimientos comerciales. Dicho precepto, que por cierto está redactado en términos muy similares a los del Art. 38 a) de la Ley andaluza, fue recurrido por resultar contrario a derecho por establecer criterios, a juicio del recurrente "inconcretos, vagos y absolutamente discrecionales por lo que no suministran pautas objetivas sobre las que sustentar la decisión administrativa, colocando al promotor en una situación de inseguridad jurídica". A pesar de estas alegaciones el Tribunal afirma, en relación a la norma impugnada que "si bien acude a la técnica de los conceptos jurídicos indeterminados, ello es perfectamente admisible e incluso recomendable, dada la cambiante realidad social sobre la que ha de operar el aplicador de la norma, toda vez que, además, dichos criterios no abren el paso a un ámbito de discrecionalidad en el que la Administración pueda escoger entre distintas soluciones todas ellas lícitas, sino que más limitadamente exigen una interpretación jurídica conducente al agotamiento de una única interpretación válida, y permiten someter a contradicción lógica la decisión que en cada caso pueda adoptar la Administración, correspondiendo en última instancia a los órganos de la jurisdicción el control de la decisión administrativa desde los parámetros legales". 
Ahora bien, notemos que la amplia discrecionalidad administrativa trae su causa en la propia norma reguladora de la licencia. Estamos ante una norma de carácter finalista. Es el legislador el que propicia ese margen amplio de actuación, el que encomienda a la Administración la tarea de arbitrar, ponderar, y a la vista de los diferentes intereses en juego realizar un balance costes-beneficios. Todo ello con el fin de alcanzar un crecimiento armónico y equilibrado de las estructuras comerciales ${ }^{59}$.

El problema que esta amplitud de miras plantea es el del ejercicio legítimo de la potestad autorizatoria y su posterior control jurisdiccional. En este sentido hay que decir que las Sentencias recaídas al respecto son escasas. En Andalucía la litigiosidad judicial en este tema es prácticamente inexistente. Es posible que ello resulte así, porque han sido muy pocas las licencias comerciales que hasta la fecha se han denegado. Quizás la principal virtualidad de la intervención autonómica sobre este tipo de establecimientos iniciada en 1996, haya sido la introducción de cargas modales, que pueden acompañar a las licencias otorgadas, y de medidas correctoras paliativas de los impactos negativos producidos por ellos. Veámoslo.

A medida que se han ido desarrollando las distintas normativas autonómicas sobre comercio interior también se han ido introduciendo en las respectivas regulaciones de las licencias comerciales, la exigencia de medidas correctoras que frenen los efectos nocivos producidos por los grandes comercios (v. gr. costes sociales o laborales, efectos sobre el medio natural, sobre las previsiones de usos del suelo, repercusión sobre la oferta y la demanda, etc.).

También en Andalucía se ha hecho así. El mismo Art. 38 que comentamos, expresamente se refiere en su apartado b) a la "valoración de las medi-

\footnotetext{
${ }^{59}$ Seguimos en este punto al Prof. TORNOS MÁS, J., quien en un magnífico trabajo sobre la "Discrecionalidad e intervención administrativa económica" (en Vol. col. "Discrecionalidad Administrativa y control judicial". Madrid 1996. Págs. 461 y ss.) realiza un estudio sobre la peculiar estructura que presentan las normas administrativas en el campo económico y su control judicial. Para el autor, la estructura de las normas que establecen la intervención administrativa en la economía, comporta un necesario replanteamiento de las técnicas de la reducción de la discrecionalidad. Este replanteamiento pasa por centrar el interés en los aspectos procedimentales y organizativos. Cuando la norma renuncia a definir de modo preciso el contenido de la decisión administrativa para imponer tan sólo objetivos, cuando es el legislador el que ha originado y provocado ese margen de maniobra a la Administración, quizás ante la imposibilidad de armonizar todos los intereses en presencia en el ámbito parlamentario, en estos casos, en que la misma ponderación de intereses a proteger es difícil, el derecho procedimental y organizativo asumen un papel de primer orden.
} 
das adoptadas por el promotor en orden a corregir, en su caso, el impacto que la instalación pudiera ocasionar al comercio previamente establecido en la zona de influencia, fundamentalmente respecto a los pequeños y medianos establecimientos comerciales, por medio de actuaciones de común interés para la zona". También el Art. 36.1, al establecer la documentación que el promotor de un gran establecimiento debe acompañar a su solicitud, alude a "las medidas de integración que se pudiesen prever" (apartado f).

Estas medidas, en hipótesis, pueden ser anticipadas o propuestas por el promotor, o también venir requeridas por la Administración, al otorgar la licencia comercial, como si de cargas modales se $\operatorname{trataran}^{60}$. Su contenido resulta muy amplio, pueden referirse tanto a la integración del establecimiento en la zona de influencia (por ejemplo, mediante convenidos celebrados con los empresarios del sector), como a la incidencia sobre el medio ambiente (v. gr. medidas preventivas contra la contaminación acústica), fomento del empleo (puestos de trabajo que se crean), etc. Su utilidad no sólo se dirige a corregir los efectos nocivos de los nuevos establecimientos, sino también a potenciar las ventajas o beneficios que éstos puedan ocasionar (dinamización de la actividad comercial, aumento de la oferta comercial...).

\section{LA PLANIFICACIÓN DEL COMERCIO INTERIOR: EL PLAN AN- DALUZ DE ORIENTACIÓN COMERCIAL}

Una de las novedades principales que introdujo la Ley 6/2002 de modificación de la Ley de Comercio Interior de Andalucía ha sido la regulación del Plan Andaluz de Orientación Comercial. De este modo, la intervención autonómica sobre los grandes establecimientos va a servirse de dos instrumentos principales: la autorización y la planificación ${ }^{61}$. Ambas modalidades de actua-

${ }^{60}$ Parece que, hoy en día, la moderna actividad de intervención de la Administración se desarrolla a través de técnicas autorizatorias acompañadas de cargas modales, más que a través de la figura clásica de la concesión administrativa.

${ }^{61}$ La utilización de instrumentos de planificación al servicio de la ordenación del sector comercial ha sido una de las notas caracterizadoras de las leyes autonómicas de comercio interior. Vid., por ejemplo, en Aragón, el Plan General para el Equipamiento Comercial de Aragón aprobado por Decreto 124/1994, de 7 de junio; o en Cataluña, el Plan territorial sectorial de equipamientos comerciales, aprobado por Decreto 245/1997, de 16 de septiembre. Dicho Plan fue declarado nulo por Sentencia del Tribunal Superior de Justicia de Cataluña núm. 46/2002, de 26 de junio. El motivo de la anulación fue la falta de información pública, considerándose insuficiente el trámite de información del proyecto. El Tribunal analiza el alcance y contenido del plan y su naturaleza jurídica. 
ción se conectan en la propia ley desde el punto en que el principal criterio para otorgar o denegar la licencia comercial como ya se ha señalado es el de su adecuación al Plan Andaluz de Orientación Comercial.

El nombre con el que se presenta el citado Plan: "Plan Andaluz de Orientación Comercial" es indicativo, al menos aparentemente, de su carácter y significado. El objeto del Plan será precisamente "orientar la dotación de los grandes establecimientos comerciales en Andalucía, de forma que el crecimiento de la estructura comercial se lleve a cabo de manera gradual y equilibrada, de acuerdo con la situación de la oferta y la demanda de la zona afectada, dando respuestas a las expectativas y necesidades del sector", según proclama el Art. 30.1 de la Ley. Es decir, si el objetivo es orientar, parece que estamos ante una planificación de carácter indicativo, no vinculante. Sin embargo, tal carácter queda desdibujado a continuación, ya que según establece el mismo Art. 30 en su apartado 2, el contenido del Plan Andaluz de Orientación Comercial habrá de tenerse en cuenta por la Consejería competente en materia de comercio interior al resolver los procedimientos relativos a las licencias comerciales de los grandes establecimien$\operatorname{tos}^{62}$. Y en el mismo sentido, como se ha señalado anteriormente, el Art. 38 determina que el otorgamiento o denegación de la licencia comercial deberá acordarse teniendo en cuenta su adecuación al mencionado Plan.

El contenido del Plan Andaluz de Orientación Comercial, que en ningún caso puede incluir la localización de los futuros grandes establecimientos comerciales, se describe en el Art. 31 de la Ley ${ }^{63}$. De su análisis puede deducirse que el plan diseñado por el legislador en realidad constituye un estudio de mercado $^{64}$, que realiza un balance comercial o análisis de la relación oferta-

\footnotetext{
62 Por eso mismo, el Art. 34 permite que se acuerde la suspensión del otorgamiento de las licencias comerciales, por un período no superior a seis meses, en los supuestos de revisión del Plan Andaluz de Orientación Comercial (Art. 34).

63 Como mínimo incluirá: a) La evaluación de la oferta comercial en Andalucía por zonas comerciales y sectores de actividad, así como la cuantificación de la demanda comercial por zonas y grupo de gasto; b) La identificación de los desajustes entre oferta y demanda en las diferentes zonas comerciales analizadas; c) Las medidas que posibiliten la integración de los establecimientos comerciales sometidos a licencia en la estructura comercial de la zona donde pretendan implantarse; y d) La caracterización de las diferentes tipologías de equipamientos comerciales.

64 También debe presentar un estudio de mercado, entre la documentación adjunta a la solicitud, el promotor o promotores de un gran establecimiento comercial (Art. 36.1.h). El contenido que debe incluir dicho "Estudio de mercado" ha sido objeto de regulación en el reciente Decreto $208 / 2007$, de 17 de julio.
} 
demanda en las diferentes zonas territoriales de Andalucía. Se trata de un plan económico de carácter sectorial.

La Ley ordena que se formulará mediante acuerdo del Consejo de Gobierno y se aprobará mediante Decreto, en ambos casos a propuesta del titular de la Consejería competente en materia de comercio interior, oída la Comisión Asesora de Comercio Interior de Andalucía. También establece el legislador su periodo de vigencia, cuatro años, transcurrido el cual debe procederse a su revisión. Esto es lógico, ya que estamos ante una planificación dinámica, cuyo objeto de ordenación está en constante evolución.

En ejecución de lo establecido en la Ley de Comercio Interior de Andalucía el 24 de junio del año 2003, se aprobó mediante Decreto 182/2003, el primer Plan Andaluz de Orientación Comercial. En la fecha en que se redactan estas líneas, se ha dado luz verde al segundo, concretamente para el cuatrienio 2007-2010. El Decreto aprobatorio 208/2007, lleva fecha de17 de julio $^{65}$. Una de las novedades que presenta este nuevo Plan será precisamente incorporar una nueva metodología de evaluación de la oferta y la demanda comercial por zonas, sectores de actividad y grupos de gasto.

El protagonismo creciente que ha adquirido el Plan Andaluz de Orientación Comercial se refleja en la Disposición Adicional Segunda de la Ley andaluza $^{66}$. En tal Disposición se ordena que el planeamiento urbanístico general que prevea la localización de grandes establecimientos comerciales o disponga sobre determinados terrenos la compatibilidad de dicho uso, se someterá a informe no vinculante de la Consejería competente en materia de comercio, que versará exclusivamente sobre su adecuación al Plan Andaluz de Orientación Comercial previsto en esta Ley y que deberá evacuarse en el plazo máximo de dos meses $^{67}$.

\footnotetext{
${ }^{65}$ La reciente norma, además de incorporar el citado Plan, como Anexo, aborda también otras cuestiones, desarrollando la Ley de Comercio Interior de Andalucía en determinado puntos, concretamente los Arts. 38. 36.1.h y DA Segunda de la Ley.

${ }^{66}$ Que fue añadida al texto originario de la Ley del Comercio, por la Ley 13/2005, de 11 de noviembre, de Medidas para la Vivienda Protegida y el Suelo y modificada por Ley 1/2006, de 16 de mayo.

${ }^{67}$ El Decreto aprobatorio del nuevo Plan Andaluz, aprovecha la ocasión y regula en su Capítulo IV (Arts. 19 y ss.) el contenido de dicho informe.
} 


\section{LA DIRECTIVA EUROPEA SOBRE "SERVICIOS" Y SU INCI- DENCIA EN LA REGULACIÓN DE LOS GRANDES ESTABLE- CIMIENTOS COMERCIALES}

El 12 de diciembre de 2006 fue aprobada, por el Parlamento Europeo y el Consejo, la Directiva 2006/123/CE relativa a los servicios en el mercado interior, más conocida como Directiva Bolkestein por el comisario holandés que la impulsó, Frits Bolkestein. Se trata de una Directiva de extraordinaria importancia $^{68}$, que ha resultado muy polémica desde su origen, y cuyo plazo de transposición finaliza el 28 de diciembre del 2009.

El principal objetivo de esta nueva Directiva es crear un auténtico mercado interior de servicios para el año 2010, facilitando la libertad de establecimiento y la libertad de prestación de servicios en la Unión Europea. También tiene como finalidad ampliar la posibilidad de elección de los destinatarios de los servicios y mejorar la calidad de tales servicios, tanto para los consumidores como para las empresas usuarias de servicios.

Los instrumentos establecidos para alcanzar tales fines son los siguientes: a) Simplificar los procedimientos y trámites aplicables al acceso a una actividad de servicios y a su ejercicio ${ }^{69}$, asegurando que los procedimientos y trámites aplicables a las actividades de servicios son los indispensables y que no existe solapamiento entre ellos, ni en el contenido, ni en la finalidad. En con-

${ }^{68}$ Cfr. FERNÁNDEZ RODRÍGUEZ, TOMÁS RAMÓN ("Un nuevo Derecho Administrativo para el mercado interior europeo". Revista de Derecho Constitucional Europeo, no 5, 2006. Págs. 189-197), quien llega a afirmar que "es la llave que abre una nueva y definitiva etapa en el proceso de construcción del mercado interior único". El autor reconoce que en los veinte años transcurridos desde la entrada en vigor del Acta Única Europea se han dado pasos muy importantes en esta dirección; sin embargo, la implantación de un mercado único y auténticamente libre va mucho más allá y requiere revisar -fuera ya del ámbito de los antiguos servicios públicos- innumerables disposiciones de todo tipo para comprobar si resultan obstáculo para la libertad de establecimiento y prestación de servicios, y en ese caso si pueden considerarse justificados y, en consecuencia mantenerse, o, por el contrario, deben ser eliminados.

En relación a esta nueva Directiva puede verse, además, el trabajo de TOMÁS DE LA CUADRA-SALCEDO JANINI, "Quo Vadis, Bolkestein? ¿Armonización o mera desregulación de la prestación de servicios?”, Revista de Derecho Constitucional Europeo, no 5, 2006. Págs. 237-280. También, CÁNTARO, ANTONIO, "El trabajo en la Constitución Europea: de Tocqueville a Bolkestein”. Revista de Derecho Constitucional Europeo, no 5, 2006. Págs. 31-64.

${ }^{69}$ A juicio de la Directiva, los obstáculos al libre establecimiento y prestación de servicios con frecuencia provienen de un exceso de trámites administrativos (Cdo. № 3). 
creto, la Directiva prevé la creación de ventanillas únicas en las que un prestador podrá realizar todos los trámites necesarios para ejercer su actividad, así como la obligación de posibilitar la realización de estos procedimientos por vía electrónica; b) Eliminar los obstáculos jurídicos y administrativos al desarrollo de las actividades de servicios, entre otros medios, a través de las evaluaciones sobre la compatibilidad de los regímenes de autorización; c) Facilitar la libre prestación temporal de servicios transfronterizos; d) Reforzar los derechos de los consumidores como usuarios de los servicios; e) Garantizar la calidad de los servicios; f) Instaurar una cooperación administrativa efectiva entre los Estados miembros.

Siguiendo a TOMÁS RAMÓN FERNÁNDEZ, podemos afirmar que el núcleo de la Directiva es establecer un marco general para los regímenes de autorización ${ }^{70}$. Partiendo del principio de proporcionalidad, el Art. 9 de la Directiva establece que los Estados miembros, sólo podrán supeditar el acceso a una actividad de servicios y su ejercicio a un régimen de autorización cuando dicho régimen no sea discriminatorio para el prestador, resulte indispensable por una razón imperiosa de interés general y no pueda conseguirse el objetivo mediante una medida menos restrictiva (por ejemplo, mediante un control a posteriori). Si estas condiciones se cumplen, será legítimo establecer un control preventivo de tipo autorizatorio, pero el otorgamiento o denegación de la autorización deberá basarse en criterios que delimiten el ejercicio de la facultad de apreciación con el fin de que dicha facultad no se ejerza de forma arbitraria ${ }^{71}$.

A la vista del contenido de esta nueva Directiva comunitaria, se plantea el tema de su posible repercusión en el régimen de la licencia comercial específica que venimos examinando en este trabajo ${ }^{72}$.

\footnotetext{
${ }^{70}$ Cfr. "Un nuevo Derecho Administrativo...”, pág. 192.

${ }^{71}$ Las características que deben observar dichos criterios se concretan en el Art. 10 de la Directiva.

72 Para un examen de la normativa nacional de los distintos países de la Unión Europea en materia de apertura de grandes establecimientos comerciales véase PALAU RAMÍREZ, F. "La regulación de la apertura de establecimientos comerciales en la Unión Europea". Marcial Pons. Madrid-Barcelona, 2003. En dicha obra, el autor recuerda cómo el Tribunal de Justicia de las Comunidades Europeas tiene declarada la compatibilidad de las legislaciones nacionales sobre apertura de establecimientos comerciales con el principio comunitario de libre circulación de mercancías y con la normativa comunitaria de defensa de la competencia (ob. cit. pág 110). Vid. CASES, L y FONS. F, "La implantación de grandes establecimientos comerciales". Madrid, 1998. Págs. 92 y ss.
} 
El Art. 2 delimita su ámbito de aplicación señalando que la Directiva "se aplicará a los servicios prestados por prestadores establecidos en un Estado miembro". A continuación menciona una serie de actividades o servicios que se consideran excluidos ${ }^{73}$. El concepto de "servicio" se define en el Art. 4 como "cualquier actividad económica por cuenta propia, prestada normalmente a cambio de una remuneración, contemplada en el artículo 50 del Tratado"74. Se trata ciertamente de un concepto muy amplio ${ }^{75}$. Aunque no se menciona expresamente, dado que la norma habla de "cualquier actividad económica" podría entenderse también incluida la actividad comercial ${ }^{76}$.

Desde el punto de vista del procedimiento la licencia comercial estaría también afectada por la nueva Directiva, ya que la norma comunitaria se refiere a todos los procedimientos en virtud de los cuales el prestador o el destinatario del servicio están obligados a hacer un trámite para poder acceder a una actividad ${ }^{77}$.

${ }^{73}$ Así, los servicios no económicos de interés general; los servicios financieros (como los bancarios, de crédito, de seguros y reaseguros, de pensiones de empleo o individuales, de valores, de fondos de inversión y de pagos); los servicios de comunicaciones electrónicas en lo que se refiere a los ámbitos que se rigen por las Directivas en la materia; los servicios de transporte, incluidos los portuarios; los servicios de las empresas de trabajo temporal; los servicios sanitarios; los servicios audiovisuales; las actividades de juego por dinero; las actividades vinculadas al ejercicio de la autoridad pública; determinados servicios sociales; servicios de seguridad privados; servicios prestados por notarios y agentes judiciales designados mediante un acto oficial de la Administración (Art. 2.2).

${ }^{74}$ El Art. 50 del Tratado señala que se considerarán como servicios las prestaciones realizadas normalmente a cambio de una remuneración, en la medida en que no se rijan por las disposiciones relativas a la libre circulación de mercancías, capitales y personas.

${ }^{75}$ Cuyo contenido va a quedar en la práctica bastante reducido debido a las exclusiones establecidas en la propia Directiva.

${ }^{76} \mathrm{El}$ carácter prestacional de la actividad económica aparece un tanto desdibujado si lo comparamos con la redacción del Art. 50 del Tratado, y en cambio, en la Directiva se destaca el elemento económico o de remuneración.

Ya hemos visto cómo en algunas leyes autonómicas sobre comercio interior se incluye dentro de la actividad comercial la prestación de "servicios".

${ }^{77}$ La Directiva define en su Art. 4.6 lo que entiende por "Régimen de autorización": "cualquier procedimiento en virtud del cual el prestador o el destinatario están obligados a hacer un trámite ante la autoridad competente para obtener un documento oficial o una decisión implícita sobre el acceso a una actividad de servicios o su ejercicio". Y en el Cdo. 39 se aclara: "El concepto de Régimen de autorización debe abarcar, entre otros, los procedimientos administrativos me- 
¿En qué sentido podría afectar la Directiva a la regulación actual de la licencia comercial? En nuestra opinión, al margen de otras incidencias de no menor calado ${ }^{78}$, la principal repercusión de esta nueva norma comunitaria en el régimen jurídico de la licencia comercial se produciría en relación a los criterios establecidos para el otorgamiento de la misma, que deberían revisarse. En concreto, el Art. 14 de la Directiva establece en relación a las autorizaciones una serie de requisitos cuya exigencia queda prohibida. Entre ellos, cabe destacar el número 5, que reza así: "la aplicación, caso por caso, de una prueba económica consistente en supeditar la concesión de la autorización a que se demuestre la existencia de una necesidad económica o de una demanda en el mercado, a que se evalúen los efectos económicos, posibles o reales, de la actividad o a que se haga una apreciación de si la actividad se ajusta a los objetivos de programación económica fijados por la autoridad competente; esta prohibición no afectará a los requisitos de planificación que no sean de naturaleza económica, sino que defiendan razones imperiosas de interés general".

Entendemos que tal prohibición afectaría de lleno al sentido y a la filosofía que inspira tanto la regulación actual de la licencia comercial como el Plan Andaluz de Orientación Comercial, que constituye ciertamente una planificación de carácter económico. Así pues, al menos, el núcleo de la regulación vigente de la licencia de grandes establecimientos debería ser revisado. No así otros aspectos, que pueden incidir en el otorgamiento o denegación de la licencia, y quedan fuera del objeto de esta Directiva, como por ejemplo, las normas de tráfico rodado, normas relativas a la ordenación del territorio, urbanismo y ordenación rural, normas de construcción, ni a las sanciones administrativas impuestas por no cumplir dichas normas ${ }^{79}$.

diante los cuales se conceden autorizaciones, licencias, homologaciones o concesiones, pero también la obligación, para poder ejercer una actividad, de estar inscrito en un colegio profesional o en un registro, en una lista oficial o en una base de datos, de estar concertado con un organismo o de obtener un carné profesional. La concesión de una autorización puede ser resultado no sólo de una decisión formal, sino también de una decisión implícita derivada, por ejemplo, del silencio administrativo de la autoridad competente o del hecho de que el interesado deba esperar el acuse de recibo de una declaración para iniciar la actividad en cuestión o para ejercerla legalmente".

78 Pensamos, por ejemplo, en las consecuencias de la implantación de un sistema de ventanilla única para realizar todos los trámites necesarios relacionados con la actividad comercial. No podemos en este momento realizar un estudio exhaustivo y en profundidad del contenido de la Directiva "Servicios", que excedería el objeto específico de este trabajo.

${ }^{79}$ Vid. Considerando nº 9 de la Directiva. 


\section{LAS GRANDES SUPERFICIES COMERCIALES Y EL DENOMINA- DO "URBANISMO COMERCIAL"}

La ordenación urbanística de la actividad comercial constituye un fenómeno nuevo, al menos en algunos de sus aspectos ${ }^{81}$. Tradicionalmente, el comercio ha sido siempre una actividad que se ha integrado con absoluta naturalidad en el conjunto de las funciones urbanas. La inserción del pequeño comercio en la ciudad no ha sido nunca una cuestión problemática. El uso comercial del suelo coexistía con el uso residencial sin mayores problemas, mientras que los establecimientos de tamaños mayores (almacenes, servicio de distribución, etc.) se localizaban en "suelo industrial"82.

Hoy vivimos un fenómeno nuevo. El surgimiento de nuevas formas comerciales (supermercados, hipermercados, galerías comerciales...) con formas y tamaños que no se adaptan a las tramas urbanas fundamentales, vienen a cambiar la situación. También se plantea el tema de la implantación de grandes superficies en suelo no urbanizable, en principio excluido por la Ley y por el Plan de cualquier tipo de desarrollo urbano.

La proliferación de estos nuevos establecimientos comerciales plantea una serie de problemas urbanísticos (saturación del tráfico, incidencia en la red viaria y en el sistema de transportes, desertización de los centros históricos

${ }^{80}$ Sobre el tema Vid. PÉREZ FERNÁNDEZ, J.M. "Urbanismo comercial y libertad de empresa". Marcial Pons, Madrid, 1998; GÓMEZ-REINO Y CARNOTA, E. "El urbanismo comercial", en la obra colectiva dirigida por el mismo profesor, "Ordenamientos urbanísticos. Valoración crítica y perspectivas de futuro". Marcial Pons. Madrid, 1998; MARTÍNEZ DE PISÓN, I. "Urbanismo comercial: el régimen de apertura de grandes establecimientos comerciales en la Ley 7/1996, de 15 de enero, de Ordenación del Comercio Minorista”, RAP nº 145, 1998. Pág. 363 y ss; RODRÍGUEZ VELARDE, B. "El urbanismo comercial". Madrid, 2000.

${ }^{81}$ La sociedad, el territorio y la ciudad siempre han guardado una estrecha relación con la actividad del comercio. Pensemos por ejemplo en el papel esencial que el comercio ha tenido históricamente en el crecimiento y desarrollo urbano. Diversas ciudades y pueblos surgieron por motivos comerciales, en torno a una feria o mercado. Y, hoy en día, el comercio sigue siendo uno de los principales agentes de transformación de la ciudad y motor de estructuración urbana (vid. la capacidad del pequeño comercio de crear nuevos núcleos de centralidad urbana). También los cambios sociales determinan con frecuencia modificaciones en las formas y modalidades de venta.

82 FERNÁNDEZ RODRÍGUEZ, T.R., "Urbanismo y ordenación comercial” en Vol. Col. coordinado por TORNOS MÁS, J. "Grandes establecimientos comerciales. Su ordenación e implantación”. Barcelona, 2000. Págs. 52 y ss. 
por el desarrollo del comercio en la periferia, etc.) que la Administración debe resolver ${ }^{83}$.

El llamado "urbanismo comercial" surge como respuesta a los problemas originados con la implantación de los grandes equipamientos comerciales ${ }^{84}$. BERMEJO VERA, J ${ }^{85}$, lo define como "aquella disciplina novedosa que intenta relacionar los instrumentos y técnicas del planeamiento urbanístico con las necesidades de ordenación de la distribución comercial, teniendo en cuenta, sobre todo, el impacto de las grandes superficies comerciales existentes en la ciudad, de manera que se llegue a garantizar la correcta ubicación de los establecimientos desde ambos puntos de vista".

El urbanismo comercial se sitúa en la línea divisoria entre dos realidades: el comercio y el urbanismo. Tiene naturaleza híbrida ${ }^{86}$ y se caracteriza precisamente por enfocar el problema de los equipamientos comerciales y su ubicación territorial desde una perspectiva global.

Con frecuencia, la ordenación de los grandes establecimientos se ha contemplado desde planteamientos sectoriales (legislación sectorial de comercio) o estrictamente territoriales (urbanismo). En ocasiones, el legislador ha otorgado valor adjetivo a la planificación territorial respecto a la ordenación co-

${ }^{83}$ La implantación de estos grandes equipamientos provocan, desde el punto de vista socioeconómico, el enfrentamiento entre "comercio tradicional-grandes superficies", y desde el punto de vista territorial y urbanístico, entre "centro-periferia” (Cfr. RODRÍGUEZ VELARDE, B. Ob. cit. Pág. 25).

${ }^{84}$ RODRÍGUEZ VELARDE, B. "El urbanismo comercial”. Jaén, 2002. Pág. 24.

85 Cfr. "Derecho Administrativo. Parte Especial”. Civitas. Madrid, 1994. Pág. 858.

86 RODRÍGUEZ VELARDE, B. Ob. cit. Pág. 25 y ss. El urbanismo comercial tiene que resolver dos problemas: uno, el problema de la ubicación o emplazamiento de los inmuebles, instalaciones de carácter fijo destinadas al ejercicio de la actividad comercial; y, dos, el de la localización de los espacios, en los que más o menos ocasionalmente se realicen actividades comerciales. Hasta ahora, la legislación sectorial sobre comercio, por una razón de política legislativa, ha regulado de forma diferenciada el ejercicio de la actividad comercial dentro de un establecimiento de carácter fijo (en ese ámbito se afronta la ordenación de las grandes superficies) o fuera del establecimiento comercial (campo dentro del cual se establece la regulación del comercio ambulante). Para RODRÍGUEZ VELARDE, B. no es lógico excluir del campo de estudio del urbanismo comercial, los asentamientos propios del comercio ambulante, ya que al fin y al cabo se trata de la ubicación de usos e instalaciones en el espacio (Ob. cit. Pág. 63). 
mercial y viceversa, sin alcanzar un punto de encuentro entre ambas dimensiones. Al urbanismo le ha preocupado fundamentalmente el tema de la localización y dimensiones de los establecimientos, y a la legislación sobre comercio, aspectos tales como las formas comerciales, los horarios de apertura, los tipos de venta, etc.

Para RODRÍGUEZ VELARDE, B. ${ }^{87}$, en España, en la regulación del fenómeno de los grandes establecimientos puede apreciarse la mayor impronta del factor económico sobre el urbanístico (la mayoría de las normas sobre esta materia en nuestro país han sido elaboradas y aprobadas por las Consejerías o Departamentos de Industria, Comercio y Turismo. Dichos órganos serán los competentes para decidir la instalación o no de grandes superficies comerciales y para dictar las necesarias disposiciones reglamentarias).

También desde el urbanismo se ha llevado a cabo una ordenación de los usos comerciales, especialmente en los últimos años a través de la figura de los planes especiales ${ }^{88}$. Los Ayuntamientos han pretendido así recuperar por esta vía las competencias asumidas por las Comunidades Autónomas sobre comercio interior.

Poco a poco el proceso hacia una concepción más integral de los fenómenos comerciales se va abriendo paso en las diversas legislaciones autonó-

${ }^{87}$ Ob. cit. Loc. cit. Según el citado autor, la sustantividad propia del urbanismo comercial es hoy una realidad difícilmente discutida debido al desarrollo adquirido por la legislación autonómica sobre la instalación y apertura de los establecimientos comerciales, así como a la regulación específica del hecho comercial en relación con el territorio.

Lo mismo ocurre en Europa, en la que pueden detectarse tres modelos de Urbanismo comercial: a) El modelo alemán, articulado sobre la preponderancia del plan urbanístico. Tiene el inconveniente de ofrecer insuficiencia de instrumentos urbanísticos para abordar la materia comercial; b) El modelo francés y belga, que se basa en la exigencia de licencia o autorización comercial. El francés, anterior en el tiempo, se implanta con la Ley Royer 73/1193. El sistema se centra en resolver el problema de las grandes superficies, a través de la autorización comercial, renunciando así a la ordenación-planificación global del sector comercial; c) Y el modelo italiano. Es un modelo mixto de "planificación comercial integral", que pretende regular de forma global el sector comercial, en conexión con la ordenación urbanística. Combina el plan y la autorización. Se sirve de la planificación urbanística, los planes comerciales y las autorizaciones (Ob. cit. Págs. 33 y ss.).

${ }^{88}$ En relación a este punto véase el comentario a la Sentencia de 19 de febrero de 1988 de la Sala Primera de lo Contencioso-administrativo de la Audiencia Territorial de Barcelona que desestimó un recurso interpuesto contra la aprobación definitiva del Plan Especial del Comercio Alimentario de Barcelona, (luego confirmada por STS de 28 de septiembre de 1993). 
micas. Como muestra de ello, cabe reseñar la Ley 18/2005, de 27 de diciembre, de equipamientos comerciales de Cataluña, cuyo Art. 1 señala como objeto de la misma "establecer las directrices que deben adecuar los equipamientos comerciales de los municipios de Cataluña a las necesidades de consumo y de compra de los ciudadanos e impulsar un modelo de urbanismo comercial y de ocupación y utilización racional del territorio con usos comerciales que permita un desarrollo sostenible de Cataluña”.

La temática del urbanismo comercial últimamente se ha desbordado y trascendido a la problemática de la Ordenación del Territorio ya que el planteamiento, localización y configuración de centros y grandes superficies comerciales excede en su proyección del marco estrictamente municipal y entra de lleno en los objetivos de la Ordenación del territorio. Es un tema que ha pasado por tanto a las leyes de Ordenación del Territorio y a los planes de la misma.

La Ley de Ordenación del Territorio de Andalucía de 11 de enero de 1994, incluye entre los contenidos de Plan de Ordenación del Territorio de Andalucía: "los criterios territoriales básicos para la localización de los equipamientos y servicios de ámbito o carácter supramunicipal” (dentro de los cuales se encuentran las grandes áreas y centros comerciales).

Pero además, la ordenación de las grandes superficies, puede considerarse como una actividad de planificación singular e intervención singular en el marco de la ordenación del territorio.

a) Actividad de planificación singular con incidencia territorial. Aunque la planificación comercial no se menciona expresamente en el Anexo primero de la Ley de Ordenación del Territorio de Andalucía, podría entenderse incluida en el no 14 de dicho Anexo que se refiere a "Otras actividades de planificación que se refieren a las materias que se relacionan en el Anexo II”. En este sentido cabría aplicar a la misma la regulación establecida para dichas actividades de planificación singular.

b) Actividades de intervención singular. Entre las actividades de intervención singular con incidencia en la Ordenación del Territorio que relaciona la Ley de Ordenación del Territorio de Andalucía, se encuentra en el no 13: la "Localización de grandes superficies comerciales, turísticas e industriales no previstas expresamente en el planeamiento urbanístico General". En este sentido cabe decir que la normativa aplicable con carácter preferente es la que establezca el 
planeamiento urbanístico general. Y en el supuesto de que no exista tal previsión expresa, la localización de las grandes superficies queda sometida al procedimiento de coordinación, informe ${ }^{89}$ y resolución que establece la citada Ley en sus Arts. 29 y 30.

${ }^{89} \mathrm{El}$ Informe sobre la incidencia de la gran superficie en la Ordenación del Territorio deberá versar sobre la coherencia territorial de la actuación en virtud de sus efectos en la ordenación del territorio, y señalará en su caso las medidas correctoras, preventivas o compensatorias que deban adoptarse. Se trata de un informe de carácter vinculante en caso de que sea desfavorable. 